MARCIO MichiHARU TSUKAMOTO

\title{
Desenvolvimento do Método de Partículas NA REPRESENTAÇÃo DE CoRpos Flutuantes EM ONDAS ALTAMENTE NÃO-LINEARES
}

Dissertação apresentada à Escola Politécnica da Universidade de São Paulo para obtenção do Título de Mestre em Engenharia. 


\title{
MARCiO Michiharu TSUKAMOTO
}

Engenheiro Naval

\section{Desenvolvimento do Método de Partículas NA REPRESENTAÇÃo DE CoRpos Flutuantes EM ONDAS ALTAMENTE NÃO-LINEARES}

\author{
Dissertação apresentada à Escola Politécnica \\ da Universidade de São Paulo para a obtenção \\ do Título de Mestre em Engenharia \\ Área de Concentração: \\ Engenharia Naval e Oceânica. \\ Orientador: \\ Prof. Dr. Kazuo Nishimoto
}


Tsukamoto, Marcio Michiharu

Desenvolvimento do Método de Partículas na Representação de Corpos Flutuantes em Ondas Altamente Não-lineares. São Paulo, 2006. 48p.

Dissertação(mestrado) - Escola Politécnica da Universidade de São Paulo. Departamento de Engenharia Naval e Oceânica.

1.Dinâmica de Fluidos Computacional 2.Método de Partículas (MPS) I.Universidade de São Paulo. Escola Politécnica. Departamento de Engenharia Naval e Oceânica. 


\title{
FOLHA DE APROVAÇÃO
}

\section{Marcio Michiharu Tsukamoto \\ Desenvolvimento do Método de Partículas na Representação de Corpos Flutuantes em Ondas Altamente Não-lineares}

\author{
Dissertação apresentada à Escola Politécnica da \\ Universidade de São Paulo, para a obtenção do \\ título de Mestre em Engenharia. \\ Área de Concentração: \\ Engenharia Naval e Oceânica.
}

Aprovado em:

Banca Examinadora:

Prof. Dr. Kazuo Nishimoto

Instituição: Universidade de São Paulo

Assinatura

Prof. Dr. Celso Morooka

Instituição: Universidade de Campinas

Assinatura

Prof. Dr. Júlio Romano Meneghini

Instituição: Universidade de São Paulo

Assinatura 
Aos meus Pais,

às minhas Irmãs e

à Motoe 


\section{AGRADECIMENTOS}

Ao Prof. Dr. Kazuo Nishimoto, pela orientação, paciência, apoio e incentivo.

Ao Prof. Dr. Cheng Liang Yee, pelo acompanhamento, pelas discussões e sugestões que foram de grande ajuda nas etapas iniciais do trabalho.

Aos Professores Dr. Celso Morooka e Dr. Julio Meneghini, pelas críticas construtivas e sugestões concedidas durante a qualificação.

Ao Dr. Takayuki Asanuma, pelas discussões de idéias e pelo trabalho em conjunto realizado durante boa parte do mestrado.

À todos os amigos e colegas do laboratório do Tanque de Provas Numérico, que forneceram uma estrutura que possibilitou a realização deste trabalho. Particularmente, Antonio Russo, Denis Taniguchi, Fabio Okamoto, Fernando Serboncini e Gabriel Wickler que contribuiram mais diretamente na melhor realização deste trabalho.

A todos os colegas e funcionários do Departamento de Engenharia Naval e Oceânica da Escola Politécnica da Universidade de São Paulo, que contribuíram direta ou indiretamente para a realização deste trabalho.

À CAPES (Coordenação de Aperfeiçoamento de Pessoal de Nível Superior), pela concessão da bolsa de mestrado.

À Leticia Motoe Fujikura, pelo grande apoio, incentivo e compreensão. Além da grande ajuda na elaboração e apresentação deste trabalho.

À minha família, pela compreesão e incentivo durante esta estapa da minha vida. 


\section{SUMÁRIO}

LISTA DE FIGURAS . . . . . . . . . . . . . . . . . . . . . . . . . . 9

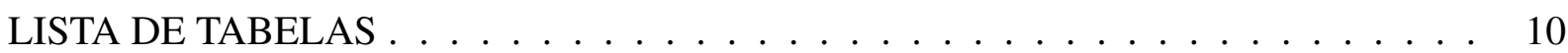

LISTA DE SÍMBOLOS . . . . . . . . . . . . . . . . . . . . 11

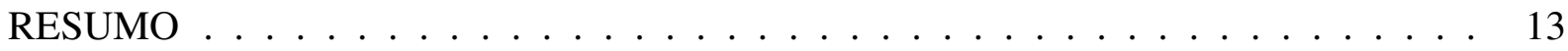

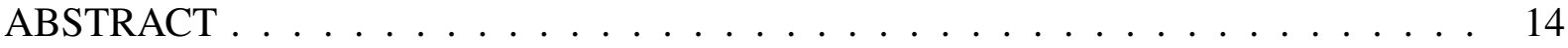

1 INTRODUÇÃO . . . . . . . . . . . . . . . . . . . . . . 15

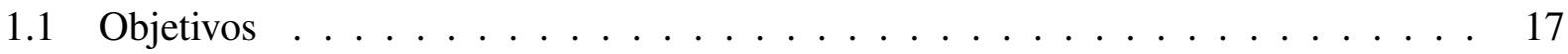

1.2 Organização do Trabalho . . . . . . . . . . . . . . . . . . . . 17

2 REVISÃO DE LITERATURA . . . . . . . . . . . . . . . . . . . 19

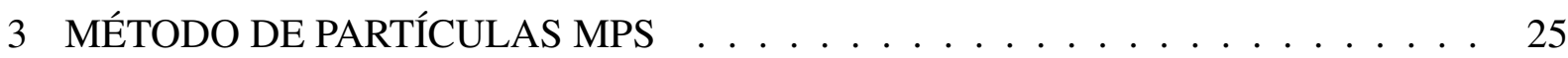

3.1 Equações Governantes . . . . . . . . . . . . . . . . . . . . . . 25

3.2 Interação entre Partículas . . . . . . . . . . . . . . . . . . . . . . 26

3.2 .1 Função Peso . . . . . . . . . . . . . . . . . . . . . . . 26

3.2.2 Densidade do Número de Partículas . . . . . . . . . . . . . . . . . 27

3.2 .3 Vetor Gradiente . . . . . . . . . . . . . . . . . . . . 28

3.2 .4 Laplaceano . . . . . . . . . . . . . . . . . . . . . . 29

3.2 .5 Incompressibilidade . . . . . . . . . . . . . . . . . . . . . 29

3.2 .6 Superfície Livre . . . . . . . . . . . . . . . . . . . . . . . . 31

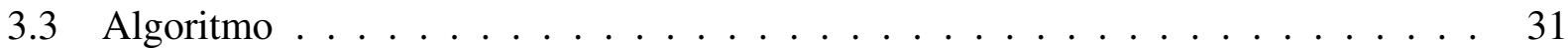

3.4 Otimização do Método de Determinação da Vizinhança . . . . . . . . . . . . . . 33

3.5 Resolução do Sistema Linear de Equações . . . . . . . . . . . . . . . . . . . . 35 


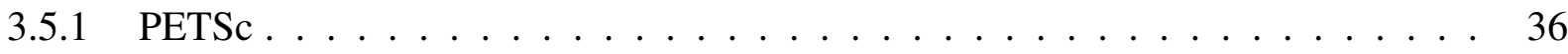

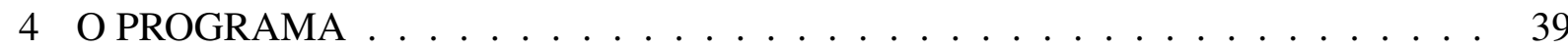

4.1 Tipos de Partículas . . . . . . . . . . . . . . . . . . . . . . . . . . . . . 39

4.2 Raio de Vizinhança . . . . . . . . . . . . . . . . . . . . . . . . . . . 40

4.3 Cálculo do passo de tempo $\ldots \ldots \ldots \ldots$. . . . . . . . . . . . 40

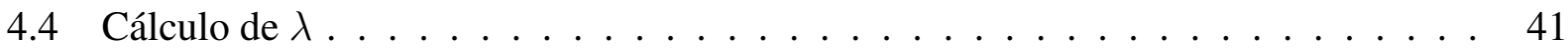

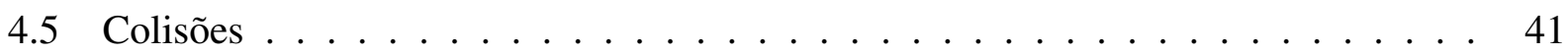

4.6 Lista de Partículas de Cada Célula . . . . . . . . . . . . . . . . . . . . . 42

4.7 Lista de Partículas Vizinhas . . . . . . . . . . . . . . . . . . . . . . . . . . 42

4.8 Dados de Entrada (Geometria) . . . . . . . . . . . . . . . . . . . . . . . 44

4.8.1 Dados da Geometria do Modelo . . . . . . . . . . . . . . . . . . . . . . 44

4.8 .2 Dados Gerais . . . . . . . . . . . . . . . . . . . . . . . . . . . . . . . . 44

4.9 Dados de Saída (Resultado da Simulação) … . . . . . . . . . . . . . . . . . 45

4.10 Visualização . . . . . . . . . . . . . . . . . . . . . . . 45

5 DESCRIÇÃO DOS ENSAIOS NUMÉRICOS . . . . . . . . . . . . . . . 46

5.1 Descrição do Equipamento Utilizado . . . . . . . . . . . . . . . . . . . . . . 46

5.2 Validação do Método . . . . . . . . . . . . . . . . . . . . . . . 46

5.3 Avaliação do Tempo Computacional . . . . . . . . . . . . . . . . . . . . . . 47

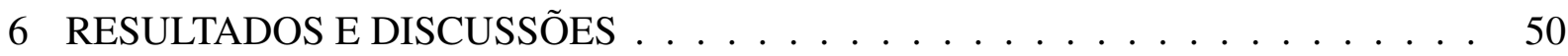

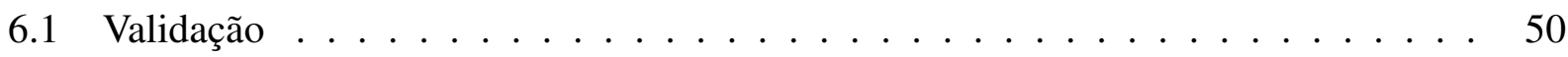

6.2 Avaliação do Tempo Computacional da Otimização do Cálculo da Vizinhança . . . 50

6.3 Avaliação do Tempo Computacional das Funções de Resolução do Sistema Linear Paralelizado do PETSc . . . . . . . . . . . . . . . . . . 53

6.4 Avaliação do Tempo Computacional da Resolução do Sistema Linear Paralelizado . 55 
6.5 Avaliação do Tempo Computacional das Funções Paralelizadas . . . . . . . . . . . 56

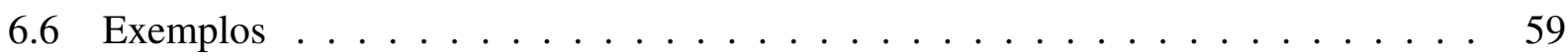

6.7 Avaliação do número de partículas necessários . . . . . . . . . . . . . . . . . . . 61

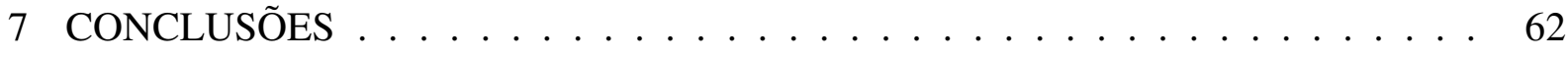

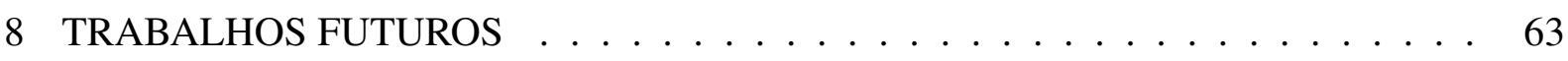

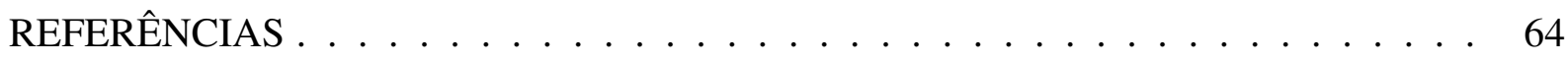




\section{LISTA DE FIGURAS}

Página

3.1 Função peso . . . . . . . . . . . . . . . . . . . . . . 26

3.2 Representação esquemática de partículas delimitando região de influência (de raio $r_{e}$ ) de uma partícula qualquer . . . . . . . . . . . . . 27

3.3 Algoritmo do método de partículas . . . . . . . . . . . . . . 32

3.4 Divisão por células . . . . . . . . . . . . . . . . . . . . . . 34

4.1 Indexação de células . . . . . . . . . . . . . . . . . . . . . . . . 42

5.1 Dimensões do modelo de ensaio de validação sem caixa . . . . . . . . . . . . . . 48

5.2 Dimensões do modelo de ensaio de validação com caixa $\ldots \ldots$. . . . . . . . . 48

5.3 Representação simplificada da caixa e seus vetores normais . . . . . . . . . . . . 48

5.4 Modelo utilizado no programa WAMIT . . . . . . . . . . . . . . . 48

5.5 Exemplo de um dos modelos utilizado para avaliar o tempo computacional . . . . . 49

6.1 Amplitude de forças horizontais obtidas nos programas MPS e WAMIT . . . . . . 52

6.2 Amplitude de forças verticais obtidas nos programas MPS e WAMIT . . . . . . . . 52

6.3 Tempo gasto no cálculo da vizinhança $\ldots \ldots \ldots$. . . . . . . . . . . . . . 54

6.4 Tempo gasto na resolução do sistema linear de um passo de tempo para diferentes números de processadores $(130177$ partículas $) \ldots \ldots \ldots 5$

6.5 Tempo gasto na resolução do sistema linear para diferentes número de processadores com diferentes números de partículas . . . . . . . . . . . . . . . . 56

6.6 Tempo gasto por funções paralelizadas . . . . . . . . . . . . . . . . 57

6.7 Caso exemplo com 7024 partículas . . . . . . . . . . . . . . . . . . . 59

6.8 Caso exemplo com 3078 partículas . . . . . . . . . . . . . . . . . 60 


\section{LISTA DE TABELAS}

Página

4.1 Distribuição das partículas nas células . . . . . . . . . . . . . . . . . 43

4.2 Matriz da lista de vizinhança . . . . . . . . . . . . . . . . 43

6.1 Amplitude de forças obtidas no programa MPS . . . . . . . . . . . 51

6.2 Amplitude de forças obtidas no programa WAMIT . . . . . . . . . . . 51

6.3 Tempo gasto no cálculo da vizinhança $\ldots \ldots \ldots$. . . . . . . . . . 53

6.4 Tempo gasto na resolução do sistema linear de um passo de tempo para diferentes números de processadores $(130177$ partículas $) \ldots \ldots$. . . . . . . . . . . . 54

6.5 Tempo gasto na resolução do sistema linear para diferentes números de processadores com diferentes números de partículas . . . . . . . . . . . . 56

6.6 Tempo gasto por funções paralelizadas . . . . . . . . . . . . . . 58 


\section{LISTA DE SÍMBOLOS}

Página

$r_{e} \quad$ Raio da vizinhança $(m) \ldots \ldots \ldots \ldots$

$h \quad$ Valor constante adicionado ao raio $r_{e}(m) \ldots \ldots \ldots \ldots$

$l_{0} \quad$ Distância média entre partículas $(m) \ldots \ldots \ldots \ldots \ldots \ldots$

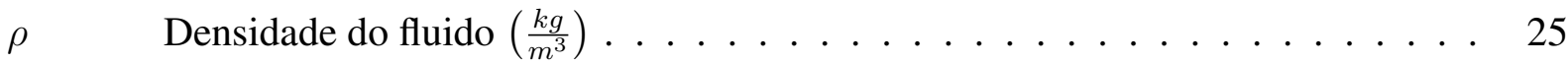

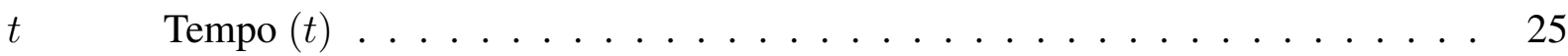

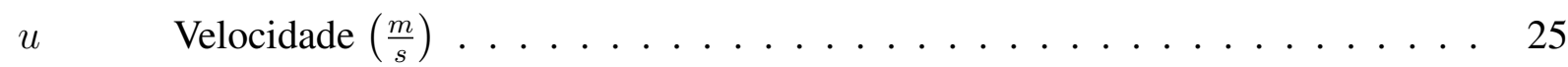

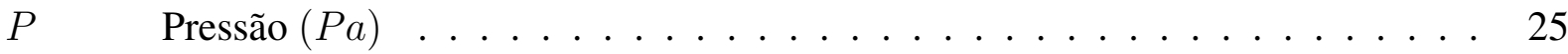

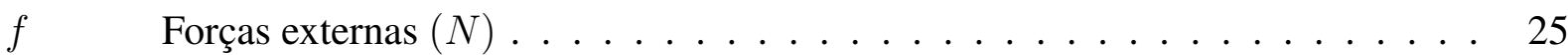

$r \quad$ Distância entre partículas $(m) \ldots \ldots \ldots \ldots$

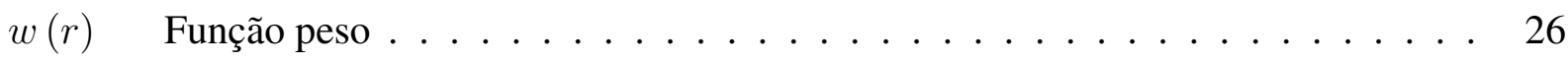

pnd Densidade do número de partículas . . . . . . . . . . . . . 27

$m \quad$ Massa de uma partícula $(k g) \ldots \ldots \ldots \ldots \ldots$

N Número de partículas em um determinado volume . . . . . . . . . . . . . 27

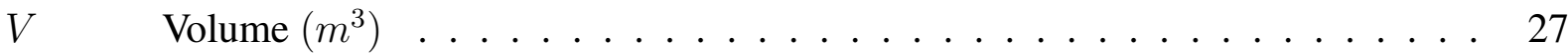

pnd $d^{0} \quad$ Densidade do número de partículas quando a vizinhança está cheia (condição de incompressibilidade $) \ldots \ldots \ldots \ldots \ldots$

$\phi \quad$ Quantidade escalar genérica $\ldots \ldots \ldots \ldots \ldots \ldots$

d Número de dimensões . . . . . . . . . . . . . . . . . 28

$\lambda \quad$ Parâmetro do operador laplaceano . . . . . . . . . . . . . . . . 29

pnd $^{*} \quad$ Estimativa inicial da densidade do número de partículas . . . . . . . . . . . . 29 
pnd $\quad$ Valor de correção da densidade do número de partículas . . . . . . . . . . . . . 29

$u_{i}^{* *} \quad$ Velocidade da partícula no novo instante de tempo . . . . . . . . . . . . 29

$u_{i}^{*} \quad$ Velocidade calculada explicitamente . . . . . . . . . . . . . 29

$u_{i}^{\prime} \quad$ Correção da velocidade . . . . . . . . . . . . . . . 30

d Número de dimensões . . . . . . . . . . . . . . . . 31

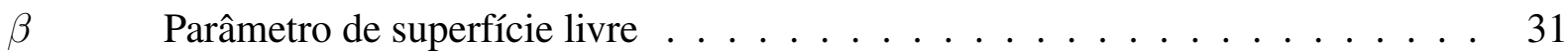

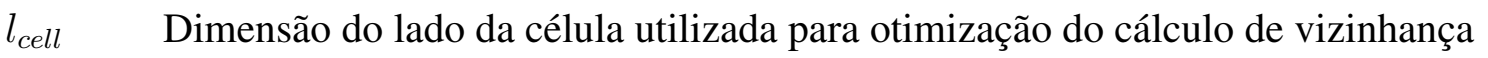

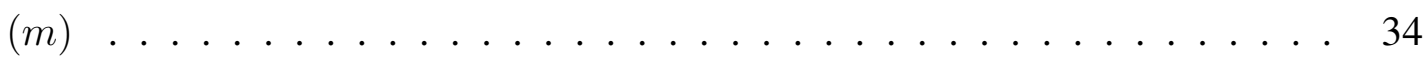




\section{DESENVOLVIMENTO DO MÉTODO DE PARTÍCULAS NA REPRESENTAÇÃO DE CORPOS FLUTUANTES EM ONDAS ALTAMENTE NÃO-LINEARES}

\section{RESUMO}

O método numérico para fluidos incompressíveis desenvolvido no presente estudo é o Moving Particle Semi-Implicit Method (MPS) que enxerga o domínio discretizado em partículas, é baseado em representação lagrangeana e não tem a necessidade de utilização de malhas. O método MPS tem como equações governantes uma forma particular da equação de Navier-Stokes e a equação da continuidade para fluidos incompressíveis e não viscosos. Os métodos de simulação de fluidos mais comumente utilizados são baseados em representação euleriana e utilizam malhas para descrever a geometria do domínio a ser simulado. Devido a essas diferenças, uma das grandes virtudes do método de partículas é a facilidade de investigação de fenômenos altamente não-lineares como o de superfície livre com quebra de ondas, de líquidos no interior de uma embarcação em movimento, de ondas batendo na parte externa do casco de um navio, etc.

Em artigos já publicados, resultados de experimentos físicos mostraram boa aderência aos resultados numéricos de simulações realizadas com o método MPS. No presente trabalho, resultados das forças de excitação das simulações com ondas regulares foram comparados com os resultados do programa Wave Analysis MIT (WAMIT) que é um programa consagrado no meio científico. Houve uma boa concordância de resultados entre os dois programas. A otimização do cálculo de vizinhança forneceu uma grande economia de tempo computacional. A maior contribuição deste estudo foi a otimização da função que resolve o sistema linear implementando no código desenvolvido um código paralelizado de uso público existente chamado Portable, Extensible Toolkit for Scientific Computation (PETSc) que proporcionou um bom ganho de desempenho. 


\title{
DEVELOPMENT OF PARTICLE METHOD REPRESENTING FLOATING BODIES WITH HIGHLY NON-LINEAR WAVES
}

\begin{abstract}
A numerical method called Moving Particle Semi-implicit (MPS) method was developed in this study to analyze incompressible fluids. It is a particle method using a lagrangean representation without any grid. The governing equations are the Navier-Stokes equation and continuity equation for incompressible and non-viscous flow. Most of the computational fluid dynamics (CFD) methods are based on eulerian representation and use grids to describe the geometry of the simulated domain. These differences make the MPS method easier to analyze highly nonlinear phenomena as free surface with wave breaking, sloshing, slamming, etc.

In previously published articles, results of physical experiments had shown good agreement with the numerical results obtained with MPS method. In the present work, results of exciting forces were compared with the results obtained with a validated program called Wave Analysis MIT (WAMIT). It had a good agreement of results between these two programs. The optimization of the neighborhood calculation function got a good economy of computational time. The greatest contribution of this study was the optimization of the linear system solver. It was made implementing in the developed code a parallelized public code called Portable, Extensible Toolkit for Scientific Computation (PETSc) that provided a good performance profit.
\end{abstract}




\section{INTRODUÇÃO}

Para resolver um determinado problema de fluidos pode-se usar basicamente 3 ferramentas:

- Métodos analíticos;

- Experiências em laboratório;

- Métodos numéricos.

O método analítico (ou método teórico) é aplicável normalmente em problemas com geometrias e condições de contorno simplificados, limitando bastante a variedade de casos solucionáveis. Porém, é muito útil na validação de métodos numéricos por serem extremamente confiáveis e rápidos de calcular.

As experiências em laboratório têm como grande vantagem trabalhar com configurações reais do problema. No entanto, possui custo elevado e muitas vezes é difícil ou impossível de reproduzir as condições reais do problema. Em alguns casos, é o único método aplicável ao problema devido à ausência de um modelo matemático que descreva o fenômeno em geometrias muito complexas.

A utilização de métodos numéricos teve um desenvolvimento impressionante nos últimos 20 30 anos graças à evolução de computadores de alta velocidade, e grande capacidade de armazenamento de dados. Inicialmente, as técnicas numéricas eram utilizadas apenas para investigação científica, mas atualmente, são amplamente utilizados pela indústria.

O método numérico possui poucas restrições, podendo ser aplicado em qualquer condição de contorno e geometrias arbitrárias, gerando resultados com grande rapidez. Porém, os resultados deste método devem ser comparados com resultados analíticos e experimentais para se ter uma confiabilidade e ter certeza de que o modelo matemático representa corretamente o problema físico.

Dentre os diversos métodos numéricos existentes, os mais conhecidos e utilizados são: método de diferenças finitas, método de volumes finitos, método de elementos finitos, método 
de painéis, entre outros. Estes métodos são extremamente úteis na investigação de fenômenos fluidos como, por exemplo: escoamento em dutos, escoamento em torno de asas de avião, estudo aerodinâmico de automóveis, entre outros.

Esses métodos, geralmente, necessitam de malhas para caracterizar as geometrias dos modelos, exigindo uma grande sofisticação do modelo para simular fenômenos que apresentam grandes deslocamentos de fluidos e de sólidos, sendo são incapazes de descrever fenômenos altamente não-lineares. Para gerar as malhas, são necessárias ferramentas de criação de malhas, que para modelos complexos, são extremamente sofisticados e em alguns casos tornam-se impraticáveis.

Para contornar essas dificuldades, foram criados outros métodos de dinâmica de fluidos computacionais. Entre esses métodos "alternativos" existe o de partícula, o qual não necessita de malhas, analisando os fluidos e os sólidos como se fossem compostos por várias partículas.

Um desses métodos de partículas é o Smoothed Particle Hydrodynamics Method (método SPH - Monaghan e Gingold 1983) que é capaz de simular escoamentos compressíveis, sólidos elasto-plásticos e problemas que envolvem os movimentos de astros. Porém, a análise de escoamento de fluidos incompressíveis ainda não foi totalmente desenvolvido.

Um outro método focado desde o início na análise de fluidos incompressíveis foi desenvolvido e chamado de Moving Particle Semi-Implicit Method (método MPS). Este é o método o qual foi estudado e desenvolvido no presente trabalho.

O métdo MPS foi desenvolvido originalmente para escoamento incompressíveis com a presença de superfície livre (Koshizuka et al., 1995; Koshizuka e Oka, 1996). O domínio é todo discretizado em partículas; ou seja, fluidos, objetos sólidos móveis e paredes fixas são consideradas como conjuntos de partículas. Não há a necessidade de utilização de malhas, é necessário apenas especificar as posições onde cada uma das partículas estão no instante inicial. Um algoritmo semi-implícito é utilizado para realizar a simulação.

No presente estudo, foram realizadas comparações entre resultados de força de excitação devido a ondas regulares obtidos pelo método MPS e por outro programa consagrado que utiliza o método de painéis. Essa comparação foi feita para comprovação da validade do método de partículas. 
Foram realizados diversos testes que mostram modelos bidimensionais onde o fluido se comporta de maneira realista.

No método MPS, o tempo computacional é elevado devido a necessidade de, em cada passo de tempo, criar uma lista de vizinhança para cada partícula, e de resolver um sistema linear de equações da ordem do número de partículas utilizadas no modelo.

Otimizações foram implementadas no cálculo de vizinhança e na resolução do sistema linear de equações com a finalidade de viabilizar o uso do método em aplicações práticas onde o número de partículas que descreve o modelo deve ser elevado.

\subsection{Objetivos}

Os objetivos do presente trabalho de pesquisa foram:

- Desenvolver um programa baseado no método de partículas;

- Validar o programa;

- Otimizar o programa;

- Paralelizar o programa para funcionar em um cluster de computadores.

\subsection{Organização do Trabalho}

- O Capítulo 2 (Revisão de Literatura) apresenta uma revisão de trabalhos publicados relacionados com o método MPS. O seu início, os outros métodos que tiveram alguma influência na sua criação, algumas das possibilidades de aplicação do método e em que estágio de desenvolvimento o método se encontra;

- O Capítulo 3 (Método de Partículas) apresenta a parte teórica do método de partículas;

- O capítulo 4 (O Programa) mostra detalhes da maneira que o código fonte do programa foi desenvolvido; 
- No capítulo 5 (Descrição dos Ensaios Numéricos), são apresentados os ensaios que foram realizados para avaliar a sua validade em aplicações reais e o tempo consumido pelos cálculos;

- No Capítulo 6 (Resultados e Discussões), estão apresentados os resultados, alguns comentários e observações dos ensaios descrito no Capítulo 5;

- No Capítulo 7 (Conclusão), estão as conclusões sobre todo o trabalho realizado. 


\section{REVISÃO DE LITERATURA}

Um método de partículas para simulação de escoamentos incompressíveis viscosos com fragmentação de fluido foi apresentado em Koshizuka et al. (1995). O método apresentou um grande potencial para simular geometrias e fenômenos mais complexos do que os métodos que utilizavam malhas como, por exemplo, a fragmentação do fluidos em superfície livre.

O autor citou outros métodos que utilizavam partículas. O método Smoothed Particle Hydrodynamics (SPH) foi aplicado em escoamento compressíveis (Monaghan e Gingold, 1983; Henneken e Icke, 1993), em sólidos elasto-plásticos (Libersky et al., 1993) e em simulações dos movimentos das estrelas (Gingold e Monaghan, 1982; Monaghan, 1988; Benz, 1990), mas modelos de interação de partículas para escoamentos viscosos incompressíveis ainda não tinham sido desenvolvidos.

O método Particle-in-Cell (PIC) utilizou o método de diferenças finitas com malhas para descrever o escoamento, exceto pelo termo convectivo que foi calculado utilizando partículas. O método Fluid-Implicit-Particle (FLIP) (Brackbill e Ruppel, 1986; Brackbill et al., 1988) foi um método melhorado do método PIC e foi aplicado em escoamentos viscosos incompressíveis (Umegaki et al., 1992). Um dos grandes problemas do método FLIP foi a instabilidade (Brackbill, 1988).

O método apresentado no artigo Koshizuka et al. (1995) foi baseado em modelos de interação de partículas que representam gradiente de pressão, difusão, incompressibilidade e condição de contorno de superfície livre sem nenhuma malha. Termos da difusão artificial usados em PAF (Daly et al. (1965)) e SPH não foram necessárias. Incompressibilidade foi modelado com um algoritmo como Marker-and-Cell (MAC) (Harlow e Welch, 1988), onde o cálculo foi dividido em uma parte explícita e outra implícita.

O resultado da simulação de uma coluna de fluido presa em um dos lados de um tanque retangular sendo liberada e depois chocando-se com um obstáculo foi obtida com sucesso. Grandes deformações e fragmentações do fluido foram observados, havendo uma boa aderência 
de resultados numéricos e experimentais.

Em Koshizuka e Oka (1996), o método apresentado em Koshizuka et al. (1995) recebeu o nome de "Moving Particle Semi-Implicit Method" ou simplesmente método MPS. Alguns valores de coeficiente de superfície livre e de raio de vizinhança foram testados para obter os valores que apresentem os melhores resultados. A função peso e o modelo de incompressibilidade foram modificadas, obtendo-se uma grande melhoria de estabilidade numérica e diminuição do tempo computacional.

A simulação da coluna de fluido foi repetida com as mudanças no código fonte e comparada com os experimentos de Martin e Moyce (1952), mostrando uma boa aderência de resultados mesmo quando o fluido foi fragmentado devido ao choque.

Em Koshizuka e Oka (1997), o método MPS foi utilizado para analisar a dinâmica de fluidos com interfaces fluidos-sólido, fluido-estrutura e líquido-gás.

Os autores mostraram resumidamente quais os tipos de simulações que o método MPS foi capaz de realizar até aquele momento. Modelos com ondas quebrando na praia, ondas quebrando com um objeto flutuante, uma coluna de água chocando com uma parede fina deformável, e uma mistura de água, vapor e metal líquido calculados simultaneamente foram apresentados.

Koshizuka et al. (1998a) propôs uma otimização para o cálculo da vizinhança que consistiu em determinar em cada passo de tempo as partículas vizinhas dentro de uma região de raio $r_{e}$ e em cada número determinado de passos de tempo determinar os candidatos a partículas vizinhas dentro de uma região de raio $r_{e}+h$ As partículas vizinhas eram procuradas apenas na lista de candidatos, o que diminuiu consideravelmente o número de partículas a serem checados. Foi obtida uma redução de tempo de cálculo de ordem $N^{2.0}$ para $N^{1.5}$.

Foram apresentados resultados de ondas sendo geradas e quebradas na praia. As formas das ondas tiveram uma boa aderência com resultados analíticos. Porém, foi detectado um atrito artificial que os autores dizem ser devido ao movimento desordenado das partículas.

Em Koshizuka et al. (1998b), foram apresentados as primeira aplicações do método MPS em simulações tridimensionais. Dois resultados foram mostrados. Em um deles, foi simulado uma coluna de fluido presa em um dos lados de um tanque retangular sendo solta. Os 
resultados tiveram uma boa aderência com resultados de experimentos reais. Em uma segunda experiência, aço derretido contido em um tanque cilíndrico foi liberado em uma superfície plana. A área de espalhamento do líquido ficou diferente do resultado esperado, mas para os autores isso poderia ser resolvido aumentando o número de partículas para descrever o modelo.

Para simulações tridimensionais, os autores ainda sugeriram uma diminuição do raio de vizinhança de $4.0 l_{0}$ (onde $l_{0}$ é a distância média entre partículas) utilizados nas simulações bidimensionais para $(2.0 \sim 3.0) l_{0}$ nos casos tridimensionais. Nos modelos gerados, foi percebido a presença de um número muito grande de partículas de paredes fixas devido à necessidade do programa utilizar três fileiras de partículas para definir as paredes. Isso gerou um desperdício de tempo computacional e motivou o desenvolvimento de novas técnicas para reduzir o número de partículas de parede.

Análises bidimensionais de interações fluido-estrutura com grandes deformações de interfaces foram apresentadas em Chikazawa et al. (1998), obtendo-se resultados de experimentos de um tanque oscilando horizontalmente com líquido em seu interior com paredes rígidas e flexíveis. Foi verificada a diminuição da frequêencia de ressonância com paredes flexíveis. Esses resultados tiveram boa aderência quando comparados com resultados de experiências físicas feitas em Hayama et al. (1983).

Em Ikeda et al. (1999), foram apresentadas análises de simulações de fluidos com diferentes densidades. O modelo utilizado foi composto por um recipiente com metal derretido em seu interior e um jato de água vindo de cima do recipiente que se mistura com o metal derretido. Foram feitas simulações bidimensionais e tridimensionais que foram comparadas com resultados reais medindo quanta água penetrou no metal líquido. No caso bidimensional, a água penetrou menos que em experimentos reais enquanto que no caso tridimensional teve uma boa aderência de resultados.

O método de partículas adaptado para estruturas sólidas foi apresentado em Chikazawa et al. (2001). O método fez com que as partículas se comportem como se estivessem conectadas por molas tangenciais e normais. Testes com viga engastada e placas tracionadas apresentaram bons resultados quando comparados com soluções analíticas. Testes com barra visco-plástica apresentaram resultados numéricos com boa aderência quando comparadas aos resultados 
analíticos. Testes com deformação por fluência e fratura de placa com trinca tiveram bons resultados quando comparados com resultados experimentais.

O método adaptado combinado com o método MPS original foi usado para análises de interação fluido-estrutura. Um teste de água caindo em uma barra engastada gerou uma simulação onde a água fragmentou-se e a barra engastada deslocou-se com sucesso. Ondas geradas colidindo com uma parede foram simuladas e a distribuição de pressão dessa parede teve uma boa aderência com resultados analíticos.

Em Sueyoshi e Naito (2002b), foram apresentados resultados de análises da utilização do método MPS em aplicações navais. O trabalho foi baseado no estudo do movimento de uma embarcação. Em testes de decaimento de balanço (roll) com dois navios semelhantes com centros de gravidade diferentes, e pelos gráficos dos movimentos de roll, verificou-se as diferenças dos períodos naturais. Foram feitos outros testes de decaimento com cargas sólida e líquida. Pelos gráficos de movimentos de roll percebeu-se a diferença de comportamento devido ao tipo de carga que a embarcação carrega. Em um último conjunto de ensaios foram feitos simulações de um navio intacto e avariado sujeito a ondas regulares. Foram percebidos grandes movimentos de roll em ondas com período próximas às de ressonância da embarcação intacta, e pequenas amplitudes de movimento de roll quando aplicados ondas com períodos afastados da ressonância. Nos testes com a embarcação avariada, houve a invasão de água na embarcação na parte avariada e, conseqüentemente, a perda de estabilidade.

Os autores afirmaram que o método MPS seria útil para problemas que incluam superfície livre com grandes movimentos. Eles comentam a importância do estudo de fenômenos como inundação e água invadindo a área do convés de uma embarcação, mas existe uma certa dificuldade para analisar esses problemas utilizando métodos de dinâmica de fluidos computacional mais convencionais. Com utilização do método MPS, os resultados mostrados neste trabalho provam que essas dificuldades podem ser contornadas.

Os resultados apresentados em Sueyoshi e Naito (2002b) foram mostrados novamente em Naito e Sueyoshi (2002b). Foi adicionado ao trabalho um modelo onde foi lançado na água um objeto na forma de torpedo e simulou com sucesso os fenômenos de superfície livre. Os autores afirmaram que o método gerou resultados bastante realistas. Mas os problemas 
reais são tridimensionais e para usar o método para esses casos seriam consumidos grandes recursos computacionais, chegando a conclusão de que seria necessário desenvolver uma versão do código mais sofisticada, eficiente e paralelizada.

Os resultados apresentados em Sueyoshi e Naito (2002b) foram mostrados novamente em Naito e Sueyoshi (2002a). Foram adicionados um modelo onde simula o comportamento de um navio RoRo (Roll-on Roll-off - Navios de Operação por Rolamento) alagado com movimentos de roll e outros dois modelos que validam o método MPS.

Foram feitos três tipos de ensaios no modelo do navio. O primeiro foi um modelo sem obstáculos na região alagada, o segundo foi um modelo com blocos fixos de vários tamanhos imitando a presença de automóveis e o terceiro foi um modelo com os mesmos blocos do segundo modelo, porém, com um dos blocos livre. Os resultados mostraram-se bastante realistas.

O primeiro modelo de validação mostrou a simulação de uma coluna de água presa em um dos lados de um recipiente sendo livre. Foram medidos as distâncias que a água percorre em vários instantes de tempo onde teve uma boa aderência entre os resultados numéricos e experimentais.

O segundo modelo de validação mostrou um modelo para simulação de sloshing. Foi comparada a forma da água em vários instantes de tempo e os resultados numérico e experimental tiveram uma boa aderência.

No trabalho Sueyoshi e Naito (2002a) foram apresentados resultados de simulações utilizando o método MPS. Vale destacar dois modelos tridimensionais. Uma delas foi um modelo esférico com água em seu interior mostrando o fenômeno de sloshing. O segundo foi um modelo de uma coluna de água colidindo com um objeto que tem a forma da proa de um navio e mostra a água invadindo o convés.

Em Premoze et al. (2003), foram agrupados os trabalhos desenvolvidos por outros pesquisadores sem nenhuma novidade, porém, mostra os resultados das simulações utilizando recursos gráficos mais avançados quando comparados aos trabalhos publicados anteriormente. Os autores chegaram a conclusão de que o gargalo deste método é a resolução da equação de Poisson de pressão que poderia ser resolvido paralelizando-o. Concluíram que poderiam utilizar 
esquemas de interpolação melhores para aumentar a precisão dos resultados, e que técnicas para representar visualmente os resultados ainda precisam ser melhorados devido a limitações apresentadas pelo programa de visualização criada por eles.

Em artigos como Liu et al. (2005), Liu et al. (2004), Shibata et al. (2004), Xie et al. (2004), Duan et al. (2003) e Heo et al. (2002), o método MPS é utilizado para diversas aplicações específicas da área de energia nuclear. 


\section{MÉTODO DE PARTÍCULAS MPS}

\subsection{Equações Governantes}

As equações governantes que o método utiliza como base são as equações da continuidade e de Navier-Stokes:

$$
\frac{D \rho}{D t}=-\rho(\nabla \cdot u)=0
$$

$\mathrm{e}$

$$
\frac{\partial u}{\partial t}+u \cdot \nabla u=-\frac{1}{\rho} \nabla P+\nu \nabla^{2} u+f
$$

O método MPS desenvolvido utiliza uma forma simplificada da equação de Navier-Stokes sem os termos de viscosidade e convecção (Equação de Euler):

$$
\frac{D u}{D t}=-\frac{1}{\rho} \nabla P+f
$$

No método de partículas, a equação da continuidade é utilizada em função da densidade (eq. (3.1)).

O lado esquerdo da eq. (3.3) se refere a derivada lagrangeana.

O lado direito consiste no gradiente de pressão e nas forças externas. O termo de viscosidade foi desconsiderado devido à natureza dos fenômenos estudados onde a viscosidade tem pouca influência. O efeito de tensão superficial foi descosiderado neste estudo, porém, podem ser adicionados ao método.

Todos os termos representados por operadores diferenciais devem ser substituídos pelas interações entre partículas.

Nas seções seguintes são apresentados a maneira a qual o método MPS interpreta as equações governantes e como cada um dos termos das equações podem ser considerados como interções entre partículas. 


\subsection{Interação entre Partículas}

\subsubsection{Função Peso}

No método MPS, as interações entre partículas são determinadas pela função peso $w(r)$, onde $r$ é a distância entre partículas. Ou seja, o quanto o comportamento de uma partícula é influenciada pelas partículas vizinhas é determinado pela função peso.

A função peso pode ser represatada da forma apresentada na eq. (3.4) e colocando-a em um gráfico em função da distância fica da forma mostrada na fig. 3.1.

$$
w(r)=\left\{\begin{array}{rll}
\frac{r_{e}}{r}-1 & \text { para } & \left(0 \leq r \leq r_{e}\right) \\
0 & \text { para } & \left(r_{e} \leq r\right)
\end{array}\right.
$$

Onde:

$$
r=\left|\vec{r}_{j}-\vec{r}_{j}\right|
$$

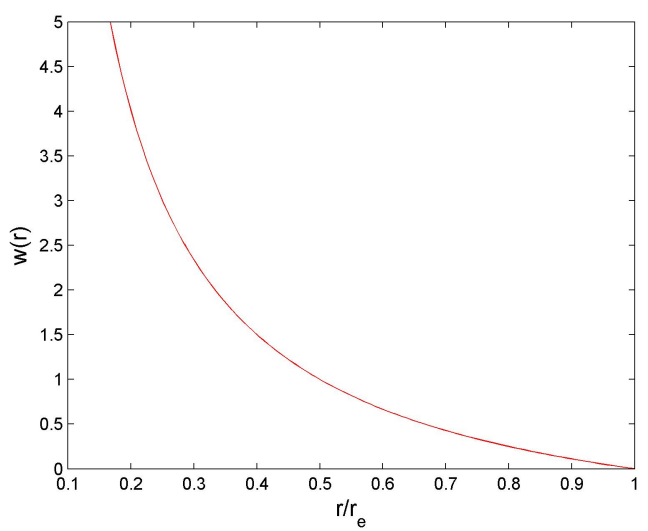

Figura 3.1 Função peso

Um esquema simplificado da distribuição das partículas para uma partícula qualquer $i$ é apresentado na fig. 3.2.

Como a área coberta pela função peso é limitada, a partícula interage com um número finito de partículas vizinhas. O raio da região de interação é determinado pelo parâmetro $r_{e}$. Comparado com uma função que cobre uma área infinita, como a função Gaussiana, a função peso (eq. (3.4)) escolhida necessita de menos memória e tempo computacional para o cálculo das interações entre as partículas. 


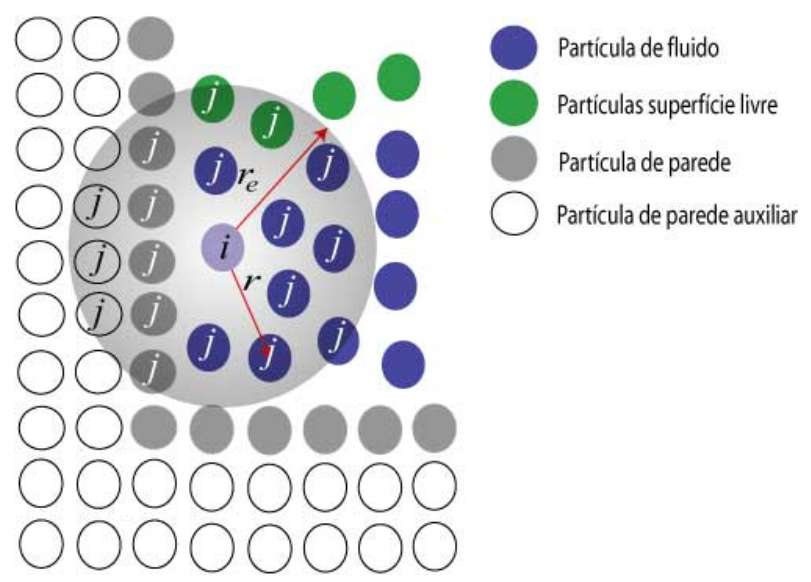

Figura 3.2 Representação esquemática de partículas delimitando região de influência (de raio $r_{e}$ ) de uma partícula qualquer

A função peso é infinita para $r=0$, o que é bom para estabilidade numérica no modelo de incompressibilidade (Koshizuka e Oka, 1996).

\subsubsection{Densidade do Número de Partículas}

O método utiliza um conceito de densidade do número de partículas (particle number density pnd) que é utilizada no lugar da densidade para garantir a propriedade de incompressibilidade, isto é, para garantir que a densidade é contínua ao longo do tempo, basta garantir que a densidade do número de partículas seja constante.

A definição da densidade do número de partículas para a coordenada $r_{i}$ onde a partícula $i$ está localizado é dada pela eq. (3.5):

$$
\langle p n d\rangle_{i}=\sum_{j \neq i} w\left(\left|r_{j}-r_{i}\right|\right)
$$

Assumindo que as partículas possuem a mesma massa $m$, tem-se que a densidade do fluido pode ser escrita como o produto da massa $m$ pelo número de partículas $N$ dividido pelo volume $V$ :

$$
\rho=\frac{m N}{V}
$$

Quando o número de partículas em uma unidade de volume é definida por $\langle N\rangle_{i}$, a relação entre $\langle p n d\rangle_{i}$ e $\langle N\rangle_{i}$ é escrito como:

$$
\langle N\rangle_{i}=\frac{\langle p n d\rangle_{i}}{\int_{V} w(r) d v}
$$


O denominador da eq. (3.7) é a integral da função $w(r)$ em toda área de vizinhança, excluindo a parte central ocupada pela partícula $i$. Combinando as eqs. (3.6) e (3.7), pode-se observar que a densidade do fluido é proporcional à densidade do número de partículas:

$$
\langle\rho\rangle_{i}=m\langle N\rangle_{i}=m \frac{\langle p n d\rangle_{i}}{\int_{V} w(r) d v}
$$

Assim, a equação da continuidade é satisfeita se a densidade do número de partículas é constante. Este valor constante é denominado $p n d^{0}$.

\subsubsection{Vetor Gradiente}

O vetor gradiente entre duas partículas $i$ e $j$ possuindo quantidades escalares genéricas $\phi_{i}$ e $\phi_{j}$ nas coordenadas $r_{i}$ e $r_{j}$ é definido por $\frac{\left(\phi_{j}-\phi_{i}\right)\left(r_{j}-r_{i}\right)}{\left|r_{j}-r_{i}\right|^{2}}$.

O vetor gradiente entre a partícula $i$ e suas partículas $j$ vizinhas é calculado definindo o peso de cada partículas $j$ vizinha (com a função peso) e tirando a sua média:

$$
\langle\nabla \phi\rangle_{i}=\frac{d}{p n d^{0}} \sum_{j \neq i}\left[\frac{\phi_{j}-\phi_{i}^{\prime}}{\left|r_{j}-r_{i}\right|^{2}}\left(r_{j}-r_{i}\right) w\left(\left|r_{j}-r_{i}\right|\right)\right]
$$

Onde $d$ é o número de dimensões (dois para casos bidimensionais e três para casos tridimensionais). Como foi apresentado em Koshizuka et al. (1998a), para melhorar a estabilidade do método, $\phi_{i}^{\prime}$ é usado no lugar de $\phi_{i}$. $\phi_{i}^{\prime}$ é calculado por:

$$
\phi_{i}^{\prime}=\min \left(\phi_{j}\right)
$$

Para qualquer $j$ satisfazendo:

$$
w\left(\left|r_{j}-r_{i}\right|\right) \neq 0
$$

Dentro do MPS, este modelo é aplicado ao termo do gradiente de pressões.

A eq. (3.9) gera forças grandes para distâncias pequenas entre partículas. Esta é uma boa propriedade para evitar a sobreposição de partículas.

Este modelo não é capaz de trabalhar com pressões absolutas. Isto é consistente com a propriedade de incompressibilidade do fluido que depende da distribuição de pressão relativa. 
Usando a eq. (3.10), forças entre partículas são sempre repulsivas porque $\phi_{j}-\phi_{i}^{\prime}$ é sempre positivo. De acordo com os autores de Koshizuka et al. (1998a), esta propriedade é boa para estabilidade numérica.

\subsubsection{Laplaceano}

O laplaceano é um operador que representa difusão. No método MPS, a difusão é modelada pela distribuição de uma certa quantidade da partícula para suas vizinhas utilizando a função peso:

$$
\left\langle\nabla^{2} \phi\right\rangle_{i}=\frac{2 d}{p n d^{0} \lambda} \sum_{j \neq i}\left(\phi_{j}-\phi_{i}\right) w\left(\left|r_{j}-r_{i}\right|\right)
$$

Onde $\lambda$ é definido por:

$$
\lambda=\frac{\int_{V} w(r) r^{2} d v}{\int_{V} w(r) d v}
$$

\subsubsection{Incompressibilidade}

Como mostrado na seção 3.2.2, a equação da continuidade diz que a densidade do fluido deve ser constante, ou seja, a densidade do número de partículas deve ser constante e igual a pnd $d^{0}$. Quando a densidade do número de partículas $p n d^{*}$ é diferente de $p n d^{0}, p n d^{*}$ é implicitamente corrigido para $p n d^{0}$ pela seguinte equação:

$$
p n d^{*}+p n d^{\prime}=p n d^{0}
$$

Onde $p n d^{*}$ é a densidade do número de partículas resultante dos cálculos explícitos e $p n d d^{\prime}$ é o valor de correção da densidade do número de partículas. Isto está relacionado com a correção da velocidade $u^{\prime}$ devido à equação da conservação de massa:

$$
\frac{1}{\Delta t} \frac{p n d^{\prime}}{p n d^{0}}=-\nabla \cdot u^{\prime}
$$

O valor da correção da velocidade $\left(u^{\prime}\right)$ é determinado pelo termo implícito do gradiente de pressão da eq. (3.3):

$$
\frac{u_{i}^{* *}-u_{i}^{*}}{\Delta t}=-\frac{1}{\rho}\left\langle\nabla P^{n+1}\right\rangle_{i}
$$


Como:

$$
u_{i}^{\prime}=u_{i}^{* *}-u_{i}^{*}
$$

Onde

$u_{i}^{* *}$ é a velocidade da partícula no novo instante de tempo;

$u_{i}^{*}$ é a velocidade calculada explicitamente; e

$u_{i}^{\prime}$ é a correção da velocidade calculada explicitamente.

Pode-se reescrever a eq. (3.16) como:

$$
u^{\prime}=-\frac{\Delta t}{\rho}\left\langle\nabla P^{n+1}\right\rangle_{i}
$$

A equação de Poisson de pressão é obtida pelas Equações (3.14), (3.15) e (3.18).

Substituindo a eq. (3.18) na eq. (3.15):

$$
\frac{1}{\Delta t} \frac{p n d^{\prime}}{p n d^{0}}=\frac{\Delta t}{\rho}\left\langle\nabla^{2} P^{n+1}\right\rangle_{i}
$$

Substituindo (3.14) em (3.19):

$$
\frac{1}{\Delta t} \frac{p n d^{0}-\left\langle p n d^{*}\right\rangle_{i}}{p n d^{0}}=\frac{\Delta t}{\rho}\left\langle\nabla^{2} P^{n+1}\right\rangle_{i}
$$

Rearranjando (3.20), obtém-se:

$$
\left\langle\nabla^{2} P^{n+1}\right\rangle_{i}=-\frac{\rho}{\Delta t^{2}} \frac{\left\langle p n d^{*}\right\rangle_{i}-p n d^{0}}{p n d^{0}}
$$

O lado direito da eq. (3.21) é representado pela diferença entre a densidade do número de partículas calculado explicitamente e o valor constante $p n d^{0}$.

O lado esquerdo da eq. (3.21) é discretizado pelo modelo laplaceano (3.12). Assim, obtemos um sistema de equações que forma um sistema linear simétrico e esparso:

$$
\frac{2 d}{p n d^{0} \lambda} \sum_{j \neq i}\left(P_{j}^{n+1}-P_{i}^{n+1}\right) w\left(\left|r_{j}-r_{i}\right|\right)=-\frac{\rho}{\Delta t^{2}} \frac{\left\langle p n d^{*}\right\rangle_{i}-p n d^{0}}{p n d^{0}}
$$

Rearranjando a eq. (3.22), tem-se:

$$
\sum_{j \neq i} w\left(\left|r_{j}-r_{i}\right|\right)\left(P_{i}^{n+1}-P_{j}^{n+1}\right)=\frac{\rho \lambda\left(\left\langle p n d^{*}\right\rangle_{i}-p n d^{0}\right)}{2 d \Delta t^{2}}
$$


A eq. (3.23) forma um sistema de equações do tipo $A x=b$ da ordem do número total de partículas . Onde os coeficientes de $A$ são os resultados do cálculo da função peso, $x$ é um vetor composto pelas incógnitas $P_{i}^{n+1}$ e $b$ é o vetor composto pelos resultados do cálculo de $\frac{\rho \lambda\left\langle p n d^{*}\right\rangle_{i}-p n d^{0}}{2 d \Delta t^{2}}$.

O termo do gradiente de pressão é calculado pelo modelo de gradiente (3.9) onde o escalar $\phi$ é substituído por $P^{n+1}$ e utilizando a eq. (3.18), obtem-se a correção da velocidade da partícula $i$ :

$$
u_{i}^{\prime}=\frac{d \Delta t}{p n d^{0} \rho} \sum_{j \neq i}\left[\frac{P_{j}^{n+1}-P_{i}^{n+1^{\prime}}}{\left|r_{j}-r_{i}\right|^{2}}\left(r_{j}-r_{i}\right) w\left(\left|r_{j}-r_{i}\right|\right)\right]
$$

\subsubsection{Superfície Livre}

As partículas que satisfizerem o critério (3.25) são consideradas partículas de superfície livre:

$$
\langle p n d\rangle_{i}^{*}<p n d^{0} \beta
$$

Onde $\beta$ é um parâmetro com valor menor que 1.0 para determinar se a partícula faz parte da superfície livre.

O valor da pressão dessas partículas é igualado a 0 devido à condição de contorno necessária para a resolução da equação de Poisson. O parâmetro $\beta$ foi avaliado em Koshizuka e Oka (1996) e pode variar de 0.8 a 0.99. Para este estudo foi utilizado o valor de 0.97 como recomendado em Koshizuka e Oka (1996).

\subsection{Algoritmo}

O algoritmo que o método de partículas segue é apresentado na fig. 3.3.

Cada passo apresentado no algoritmo tem as seguintes funções:

(1) Valores iniciais de $u$ e $r$

Dados das configurações iniciais do sistema a ser simulado. Informações como posições, velocidades, densidade, tempo de simulação, etc. das partículas.

(2) Estimativa de $u^{*}$ e $r^{*}$

Primeira estimativa da posição considerando apenas as forças externas. O movimento 


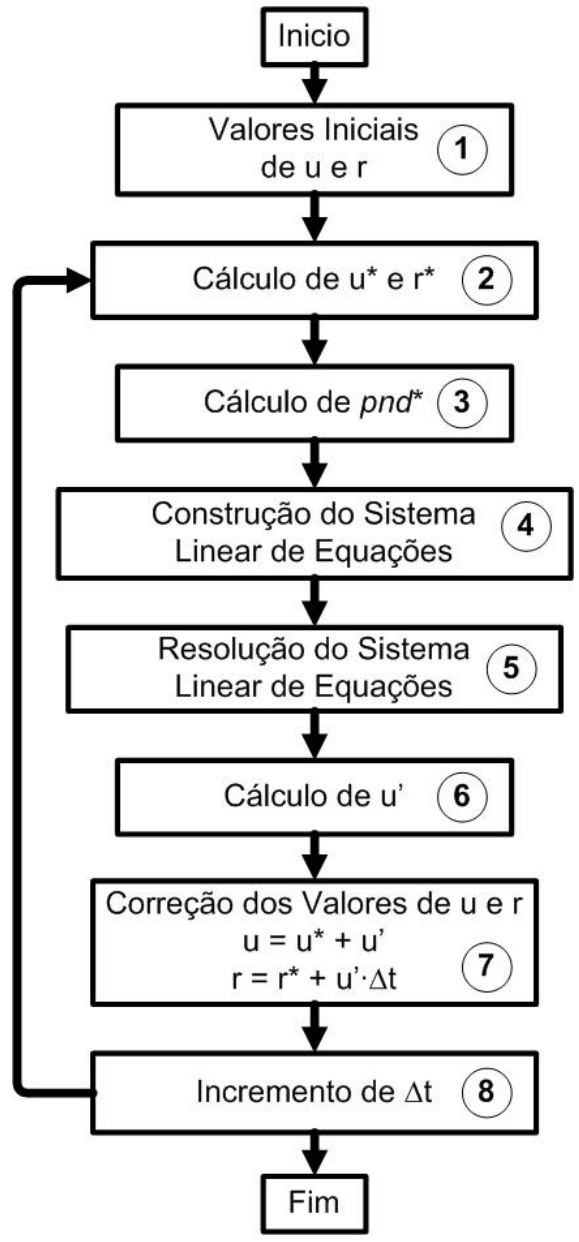

Figura 3.3 Algoritmo do método de partículas 
devido às forças externas é calculado explicitamente:

$$
\begin{aligned}
& \vec{u}_{i}^{*}=\vec{u}_{i}^{n}+f \Delta t \\
& \vec{r}_{i}^{*}=\vec{r}_{i}^{n}+\vec{u}_{i}^{*} \Delta t
\end{aligned}
$$

(3) Cálculo de $p n d^{*}$

Cálculo de $p n d^{*}$ utilizando os valores de $u^{*}, r^{*}$ e a definição de densidade de número de partículas (3.5).

(4) Equação de Poisson de pressão

Montagem do sistema de equações combinando o modelo de Incompressibilidade (3.21) e o modelo Laplaceano (3.12).

(5) Resolução do sistema linear

Com o sistema montado, utiliza-se um método de resolução de sistemas lineares esparsos para obtenção dos valores de pressão de cada partícula.

(6) Calculo $u^{\prime}$

Utilizando o gradiente de pressão e a eq. (3.18) calcula-se a velocidade $u^{\prime}$.

(7) Correção dos valores de $u$ e $r\left(u=u^{*}+u^{\prime}, r=r^{*}+u^{\prime} \Delta t\right)$

Com a velocidade $u^{\prime}$, corrige-se a estimativa inicial de velocidade e posição.

(8) Incremento de $\Delta t$

Avalia-se o programa chegou ao final da simulação. Caso não tenha chegado ao final da simulação reinicia em (Estimativa de $u^{*} e r^{*}$ ) utilizando $u$ e $r$ calculados no passo anterior.

\subsection{Otimização do Método de Determinação da Vizinhança}

Inicialmente, para determinar a lista de partículas vizinhas da partícula $i$, verificava-se a distância de todas as outras partículas $j$ e, se fosse menor que $r_{e}, j$ era incluída no grupo de vizinhança da partícula $i$. Este método para encontrar as partículas vizinhas foi a forma mais intuitiva, porém, pouco eficiente.

Foi proposto um outro método que otimiza esta procura. 
Primeiramente, divide-se o domínio em "células" quadradas com o lado $\left(l_{\text {cell }}\right)$ necessariamente maior que o valor de $r_{e}$ para que no momento de checagem das partículas vizinhas não deixe escapar nenhuma partícula que poderia estar dentro do raio $r_{e}$. No passo seguinte, verifica-se em que célula está cada uma das partículas. Tendo essas informações, é possível realizar a busca da vizinhança de uma determinada partícula procurando dentro de apenas 9 células e não mais no domínio todo. Essas 9 células são compostas pelas célula onde a partícula $i$ está localizada, e as outras 8 células são as que estão à sua volta (que têm um vértice ou um lado em comum com a célula da partícula $i$ ) como mostra a fig. 3.4. Figura 3.4 mostra a região (em vermenlho) que é feita a procura no momento do cálculo da vizinhança da partícula $i$.

Com essa mudança, o cálculo da vizinhança que era de ordem $N^{2}$ passou para $N$.

Conjuntos de testes foram feitos para avaliar o seu desempenho. As descrições dos modelos utilizados e seus resultados são mostrados em detalhes nos Capítulos 5 e 6 , respectivamente.

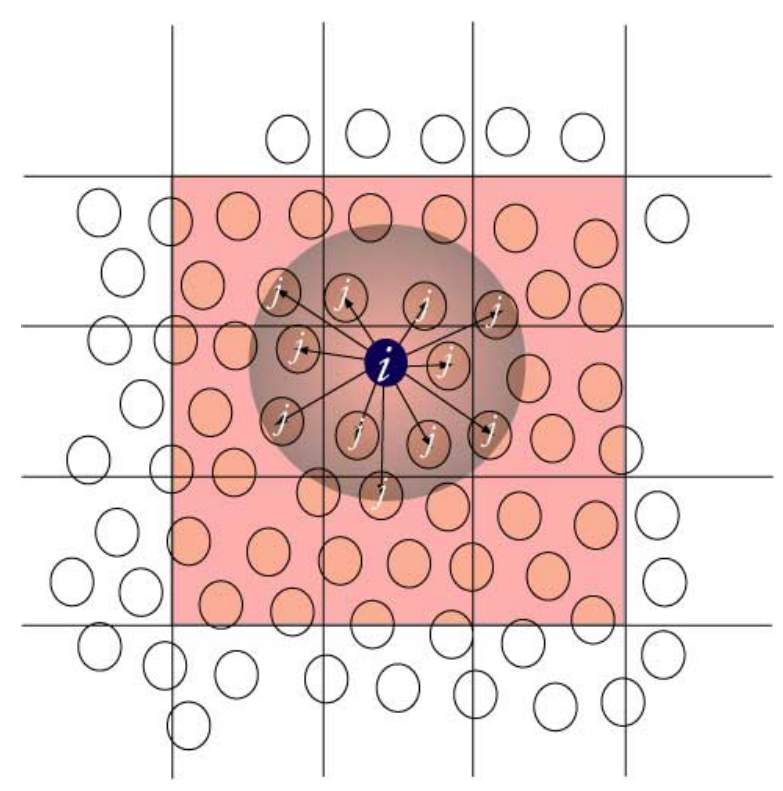

Figura 3.4 Divisão por células 


\subsection{Resolução do Sistema Linear de Equações}

Existem diversos métodos de resolução de sistemas de equações lineares. Elas são divididas em dois grades grupos: métodos diretos e iterativos. Dentre os métodos diretos estão os métodos de eliminação de Gauss e eliminação de Gauss-Jordan com fatorização da matriz $A$ na forma $A=L U$ utilizando métodos como Doolittle e Cholesky. Os métodos iterativos mais conhecidos são Jacobi, Gauss-Seidel, SOR (Successive Over Relaxation), Multigrid, gradientes conjugados entre outros.

Com a combinação das eqs. (3.21), (3.12) e (3.9) é gerado um sistema de equações com o número de incógnitas igual ao número de partículas. Assim, é formado um sistema do tipo $A x=b$ (eq. (3.23)) onde A é a matriz composta pelos coeficientes obtidos pela função peso (eq. (3.1)), $x$ é o vetor contendo as incógnitas $P_{i}^{n+1}$ e $b$ é o vetor composto pela diferença entre $p n d^{0}$ e $p n d^{*}$ multiplicados por $\frac{\rho \lambda}{2 d \Delta t^{2}}$. O método para solucionar esse sistema linear deve ser do tipo que resolve sistemas com matrizes esparsas, positivas e definidas.

O código aberto disponibilizado pelo professor Dr. Seiichi Koshizuka utiliza um método de gradientes conjugados chamado de ICCG (Incomplete Cholesky Conjugate Gradient). Este método mostrou-se bastante robusto e rápido, porém, existe uma grande dificuldade de paralelização do código, o que impossibilita a sua utilização no cluster de computadores.

Existem diversas maneiras de resolver este problema. Uma das primeiras soluções testadas foi o WSMP (Watson Sparse Matrix Package, Gupta (2001)). WSMP é uma biblioteca comercial de funções que funciona em um computador com um ou mais processadores e em um cluster de computadores. Em um computador com um processador ele mostrou-se robusto e com desempenho um pouco abaixo do método ICCG. PWSMP a biblioteca WSMP que funciona com multiprocessamento, mas os testes com cálculos multiprocessados não foram realizados.

Outra solução testada foi o PARDISO - Direct Sparse Solver da Intel Math Kernel Library Intel (2004). Ele é uma biblioteca comercial de funções que funciona em um computador com um ou mais processadores. Em um computador com um processador ele mostrou-se robusto mas com um desempenho abaixo do método ICCG. Testes com um 
computador com vários processadores não foram realizados.

A última solução testada e adotada para a continuação do desenvolvimento do programa foi o PETSc (Portable, Extensible Toolkit for Scientific Computation - Balay et al. (2001)). A biblioteca PETSc é um conjunto de funções e estrutura de dados para solução paralela de aplicações científicas de uso livre inclusive para usos comerciais. Esta biblioteca possui, entre suas funções, vários métodos para resolver sistemas lineares de equações em um computador ou em um cluster de computadores.

Conjuntos de testes foram feitos para avaliar o seu desempenho. As descrições dos modelos utilizados e seus resultados são mostrados em detalhes nos capítulos 5 e 6 , respectivamente.

\subsubsection{PETSc}

O pacote PETSc possui diversas funções capazes de resolver sistemas lineares de equações. Algumas dessas funções que foram utilizados no programa são:

- MINRES - Minimum Residual method (Paige e Saunders, 1975);

O método de gradientes conjugados pode ser visto como uma variação do método Lanczos para sistemas simétricos, positivos e definidos. O MINRES é uma das variações que pode ser aplicado em sistemas simétricos e indefinidos, onde é evitado a decomposição LU e e não sofre com uma falha no algorítmo que pode ocorrer devido a um pivô nulo se a matrix for indefinida.

- GMRES - Generalized Minimal Residual method (Saad e Schultz, 1986);

GMRES é uma extensão do minimal residual method (MINRES), voltado somente para sistemas simétricos e esparsos, para sistemas não simétricos. O método iterativo GMRES tem como objetivo minimizar a norma do resíduo do sistema.

- LGMRES - Loose GMRES (Baker et al., 2005);

O LGMRES é muito semelhante ao método do gradiente conjugado completo (CG) com precondicionador polinomial. O GMRES não mantém a ortogonalidade entre 
espaços aproximados generalizados em sucessivas reinicializações, tornando assim sua convergência vagarosa ou até mesmo levando a divergência. No LGMRES, apenas acelara o processo de convergência do m etodo GMRES.

- PCG - Preconditioned Conjugate Gradient method;

PCG é um método iterativo de gradientes conjugados para resolver sistemas simétricos, positivos e definidos. Os pré-condicionadores são artifícios utilizados que alteram a matriz de coeficientes para acelerar a solução do sistema de equações utilizando o método dos gradientes conjugados fazendo com que para sistemas não simétricos tenhas melhores condições de convergência.

- BiCG - Biconjugate Gradient method (Voevodin, 1983; Faber e Manteuffel, 1984);

BCGS é um método de gradientes conjugados utilizado para solucionar sistemas de equações não-simétrico. O método obtem o novo resíduo ortogonal em duas direções, ao invés de obter em uma única direção como é feito no método de gradientes conjugados.

- BCGS - BiCGStab method (van der Vorst, 1992);

BCGS pode ser interpretado como o produto de BiCG e GMRES aplicado repetidamente.

- TFQMR - Transpose-Free Quasi-Minimal Residual method;

O método QMR é baseado no método BiCG corrigindo alguns problemas de comportamento irregular da convergêcia. TFQMR é o método QMR sem a transposição da matris A.

- SYMMLQ - Symmetric LQ method (Paige e Saunders, 1975);

O método de gradientes conjugados pode ser visto como uma variação do método Lanczos para sistemas simétricos, positivos e definidos. O SYMMLQ é uma das suas variações que pode ser aplicado em sistemas simétricos e indefinidos, onde é evitado a decomposição LU e e não sofre com uma falha no algorítmo que pode ocorrer devido a um pivô nulo se a matrix for indefinida.

- CR - (preconditioned) Conjugate Residuals method (Poliakov e Semin, 1994). 
CR é um método iterativo que é capaz de resolve sistemas lineares simétricos e indfinidos derivado do GMRES.

Conjuntos de testes foram realizados para determinar qual método de resolução se adequa melhor ao programa desenvolvido. As descrições dos modelos utilizados e seus resultados são apresentados nos capítulos 5 e 6, respectivamente. 


\section{O PROGRAMA}

Este capítulo apresenta informações do código do programa que foi desenvolvido. Como são os dados de entrada e saída, quais são os tipos de partículas utilizadas, como as formulações são representadas dentro do código, quais valores foram adotados para determinados parâmetros, quais foram as principais dificuldades, etc.

\subsection{Tipos de Partículas}

O método MPS considera todos os sólidos e fluidos como se fossem partículas. Para o programa desenvolvido durante o estudo, foram utilizados 5 tipos diferentes de partículas:

1) fluido;

2) sólido livre;

3) parede com pressão (é feito o cálculo de pressão);

4) parede sem pressão ou parede auxiliar (não é feito o cálculo de pressão);

5) parede ou sólido com imposição de movimento.

As partículas do tipo fluido foram elementos que se movimentam livremente e foram usados para descrever o movimento de líquidos e gases. No programa foi possível fazer simulações com partículas fluidas com diferentes densidades.

As partículas do tipo sólido livre fizeram parte de um objeto sólido que se movimenta devido as forças externas tais como a gravidade e o fluido a sua volta.

As partículas do tipo parede com pressão delimitaram o espaço onde o fluido se movimenta. Neste tipo de partícula a pressão foi mensurável.

As partículas do tipo parede sem pressão ou parede auxiliar foram utilizadas apenas para garantir que as partículas fluidas não ultrapassassem a parede com pressão. Eles 
garantiram que o cálculo da densidade do número de partículas das paredes com pressão fosse feito corretamente. Existem propostas na literatura para que não seja necessário utilizá-las diminuindo, assim, o número de partículas necessárias para descrever o modelo de simulação.

As partículas do tipo parede ou sólido com imposição de movimento foram usadas quando foi necessário impor velocidades arbitrárias ignorando as forças externas. Este tipo de partícula foi útil quando o modelo de simulação possuía um gerador de onda, por exemplo.

\subsection{Raio de Vizinhança}

A região que delimitava a área de influência era um círculo de raio $r_{e}$.

Esse raio variava em função da distância média entre partículas $\left(l_{0}\right)$ utilizada na criação do modelo de simulação. Foram utilizados dois tipos diferentes de $r_{e}$, o primeiro era determinado pela função $r_{e}=2.1 l_{0}$ e utilizado no cálculo da densidade do número de partículas e no cálculo do modelo de gradiente de pressões, e o segundo era determinado pela função $r_{e}=4.0 l_{0}$ e utilizado no cálculo do laplaceano.

Existiu essa variação para economizar tempo nos cálculos sem que afetasse no resultado dos cálculos.

Uma avaliaçào do fator que multiplica $l_{0}$ para determinar $r_{e}$ foi feito em Koshizuka et al. (1995) onde mostrou como chegou nos valores de 4.0 e 2.1 .

Em Koshizuka et al. (1998b), para casos tridimensionais, sugeriram o uso de $r_{e}$ menores. Diminuindo o fator que multiplicava $l_{0}$ de 4.0 para $2.0 \sim 3.0$.

\subsection{Cálculo do passo de tempo}

Para realizar uma simulação, é necessário definir um passo de tempo de simulação que evite a sobreposição de partículas e garanta a convergência dos resultados.

O critério utilizado no programa para determinar o passo de tempo foi a condição de Courant adaptado ao método MPS dado pela equação: 


$$
\Delta t<\frac{l_{0}}{v_{\max }}
$$

Onde $\Delta t$ é o passo de tempo utilizado nos cálculos, $l_{0}$ a distância média entre partículas na condição inicial e $v_{\max }$ a velocidade mais alta de todas as partículas no instante de tempo atual.

\subsection{Cálculo de $\lambda$}

A fórmula para obter o valor de $\lambda$ utilizado no cálculo do modelo de Laplaceano (3.12) é mostrado na eq. (3.13).

Sabendo-se que $v=\pi r^{2}$ e $d v=2 \pi r d r$ para casos bidimensionais, temos:

$$
\begin{gathered}
\int_{V} w(r) r^{2} d v=\int_{0}^{r_{e}}\left(\frac{r_{e}}{r}-1\right) r^{2} 2 \pi r d r=2 \pi \int_{0}^{r_{e}}\left(r_{e} r^{2}-r^{3}\right) d r=2 \pi\left(\left.\frac{r_{e} r^{3}}{3}\right|_{0} ^{r_{e}}-\left.\frac{r^{4}}{4}\right|_{0} ^{r_{e}}\right) \\
\int_{V} w(r) r^{2} d v=2 \pi\left(\frac{r_{e}^{4}}{3}-\frac{r_{e}^{4}}{4}\right)=2 \pi\left(\frac{r_{e}^{4}}{12}\right)
\end{gathered}
$$

e:

$$
\begin{gathered}
\int_{V} w(r) d v=\int_{0}^{r_{e}}\left(\frac{r_{e}}{r}-1\right) 2 \pi r d r=2 \pi \int_{0}^{r_{e}}\left(r_{e}-r\right) d r=2 \pi\left(\left.r_{e} r\right|_{0} ^{r_{e}}-\left.\frac{r^{2}}{2}\right|_{0} ^{r_{e}}\right) \\
\int_{V} w(r) d v=2 \pi\left(r_{e}^{2}-\frac{r_{e}^{2}}{2}\right)=2 \pi\left(r_{e}^{2}\right)
\end{gathered}
$$

Concluindo que:

$$
\lambda=\frac{r_{e}^{2}}{12}
$$

Esta foi a fórmula utilizada para calcular $\lambda$ no programa.

\subsection{Colisões}

Durante os cálculos era comum ter momentos em que o gradiente de pressão não era capaz de repelir a partícula que está se aproximando. Para que não ocorresse uma sobreposição de partículas foi feito uma checagem da distância entre partículas e caso estivessem muito próximos era feito a correção da velocidade e da posição por colisão elástica. 
O critério utilizado para que seja feita o cálculo de colisão foi a seguinte:

$$
r_{i j}<0.5 \cdot l_{0}
$$

Onde $l_{0}$ é distância média entre partículas no instante inicial.

\subsection{Lista de Partículas de Cada Célula}

Para a determinação da lista de partículas contidas em cada uma das células foi utilizado uma matriz tridimensional onde os dois primeiros índices indicavam a posição da célula nas direções $x$ e $y$ e na terceira dimensão da matriz eram armazenados o número de partículas contidos na célula e os índices das partículas que se encontravam dentro da célula como mostra a tab. 4.1 referente a fig. 4.1.

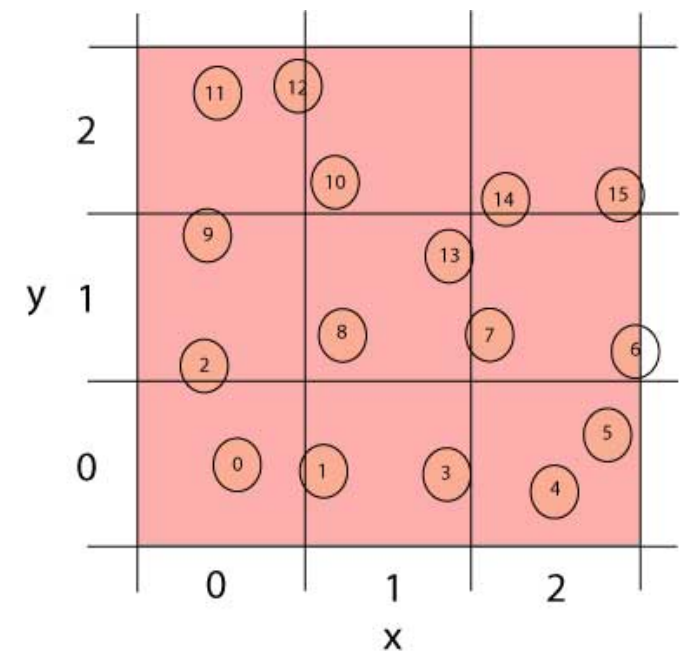

Figura 4.1 Indexação de células

\subsection{Lista de Partículas Vizinhas}

Para determinar a lista de partículas vizinhas utilizando o método otimizado o seguinte procedimento foi seguido:

1. Procura se iniciava pelas partículas contidas na célula $(0,0)$; 
Tabela 4.1 Distribuição das partículas nas células

\begin{tabular}{|c||c|c|c|c|c|}
\hline & 0 & 1 & 2 & 3 & $\ldots$ \\
\hline \hline $\operatorname{cell}\left[0,0,{ }^{*}\right]$ & 1 & 0 & & & \\
\hline $\operatorname{cell}\left[0,1,{ }^{*}\right]$ & 2 & 2 & 9 & & \\
\hline $\operatorname{cell}\left[0,2,{ }^{*}\right]$ & 2 & 11 & 12 & & \\
\hline $\operatorname{cell}\left[1,0,{ }^{*}\right]$ & 2 & 1 & 3 & & \\
\hline $\operatorname{cell}[1,1, *]$ & 2 & 8 & 13 & & \\
\hline $\operatorname{cell}\left[1,2,{ }^{*}\right]$ & 1 & 10 & & & \\
\hline $\operatorname{cell}\left[2,0,{ }^{*}\right]$ & 2 & 4 & 5 & & \\
\hline $\operatorname{cell}\left[2,1,{ }^{*}\right]$ & 2 & 6 & 7 & & \\
\hline $\operatorname{cell}[2,2, *]$ & 2 & 14 & 15 & & \\
\hline
\end{tabular}

2. Para cada partícula contida na célula $(i, j)$ era feito a checagem da distância das partículas contidas nas células $(i-1, j-1),(i-1, j),(i-1, j+1),(i, j-1),(i, j),(i, j+1)$, $(i+1, j-1),(i+1, j)$ e $(i+1, j+1)$, observando que as células com índices negativos e maiores que os índices máximos eram ignorados;

3. Com a criação da lista de partículas vizinhas concluída para as partículas contidas na célula atual passava-se para a célula vizinha;

4. Os procedimentos 2 e 3 eram repetidos até que não sobrassem mais células.

A lista de partículas vizinhas foi armazenada em uma matriz com duas dimensões onde o primeiro índice indica a numeração da partícula e na segunda dimensão eram armazenadas as partículas vizinhas sendo que o primeiro valor (índice 0) indicava a quantidade de partículas vizinhas como mostra a tab. 4.2:

Tabela 4.2 Matriz da lista de vizinhança

\begin{tabular}{|c||c|c|c|c|c|c|c|}
\hline & 0 & 1 & 2 & 3 & 4 & 5 & 6 \\
\hline \hline neigh[0,*] & 4 & 1 & 2 & 3 & 4 & & \\
\hline neigh[1,*] & 3 & 0 & 1 & 3 & & & \\
\hline neigh[2,*] & 3 & 0 & 3 & 6 & & & \\
\hline neigh[3,*] & 2 & 0 & 1 & & & & \\
\hline neigh[4,*] & 1 & 0 & & & & & \\
\hline neigh[5,*] & 0 & & & & & & \\
\hline neigh[6,*] & 1 & 2 & & & & & \\
\hline
\end{tabular}




\subsection{Dados de Entrada (Geometria)}

Os dados de entrada necessários para fazer a simulação foram divididos em dois arquivos diferentes. O primeiro era o arquivo que possuía os dados da geometria e o segundo possuía os dados de propriedades das partículas.

\subsubsection{Dados da Geometria do Modelo}

As informações das condições iniciais de simulação eram armazenados em um arquivo em formato ASCII. Dentro do arquivo estavam contidas informações de tipo, posição, velocidade, densidade do número de partículas e pressão de cada uma das partículas, além do instante de tempo e número de partículas. Caso a simulação fosse calculado desde o instante zero, eram atribuídos zeros nos valores de densidade do número de partículas e pressão. Era possível continuar os cálculos de uma simulação desde que todos os valores de posição, velocidade, densidade do número de partículas e pressão fossem conhecidos.

$\mathrm{O}$ arquivo tem a seguinte forma:

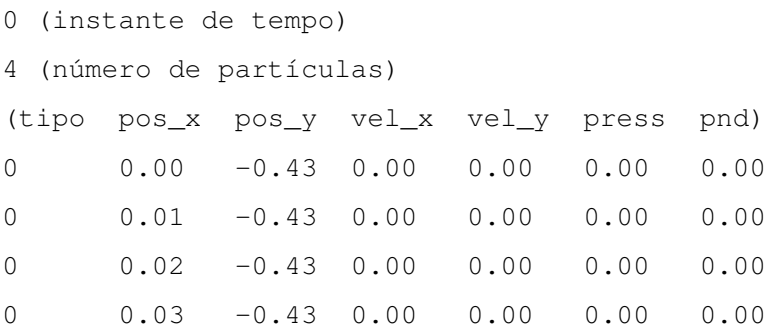

\subsubsection{Dados Gerais}

As informações da quantidade de tipos de partículas utilizadas, densidades, aceleração da gravidade, passo de tempo entre outras propriedades eram dados que estavam contidos no arquivo de propriedades.

$\mathrm{O}$ arquivo contendo os dados gerais era da seguinte forma:

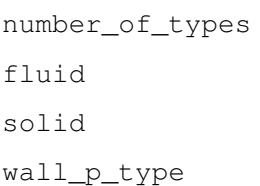

wall_p_type

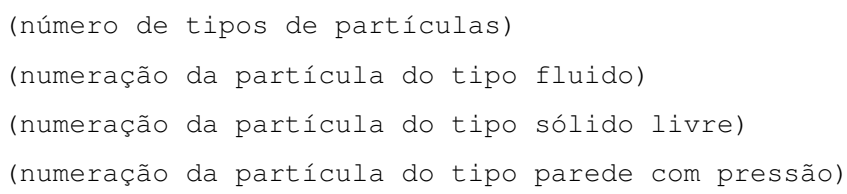




\begin{tabular}{|c|c|c|}
\hline wall_type & 3 & (numeração da partícula do tipo parede sem pressão) \\
\hline \multirow[t]{2}{*}{ wall_wm_type } & 4 & (numeração da partícula do tipo parede ou sólido com \\
\hline & & imposição de movimento) \\
\hline density_fluid & 7000.0 & (densidade da partícula do tipo fluido) \\
\hline density_solid & 1000.0 & (densidade da partícula do tipo sólido livre) \\
\hline density_wall_p & 1000.0 & (densidade da partícula do tipo parede com pressão) \\
\hline density_wall & 1000.0 & (densidade da partícula do tipo parede sem pressão) \\
\hline \multirow[t]{2}{*}{ density_wall_wm } & 1000.0 & (densidade da partícula do tipo parede ou sólido com \\
\hline & & imposição de movimento) \\
\hline gravity & 9.80665 & (aceleração da gravidade) \\
\hline max_time & 10.0 & (tempo máximo de simulação) \\
\hline max_dt & 0.001 & (passo de tempo máximo de cálculo) \\
\hline convergence & $1.0 e-6$ & $\begin{array}{l}\text { (critério de parada utilizado na resolução do sistema } \\
\text { linear de equações) }\end{array}$ \\
\hline output_interval & 0.005 & (internalo de gravação de resultados) \\
\hline average_part_distance & $1.0 e-2$ & (distância média entre partículas da geometria inicial) \\
\hline re_ratio_PND & 2.1 & $\begin{array}{l}\text { (fator de cálculo do raio da vizinhança utilizado no } \\
\text { cálculo de PND) }\end{array}$ \\
\hline re_ratio_solver & 4.0 & $\begin{array}{l}\text { (fator de cálculo do raio da vizinhança utilizado na } \\
\text { resolução do sistema linear) }\end{array}$ \\
\hline min_len & 0.5 & (fator de cálculo da distância de colisão) \\
\hline dirichlet & 0.97 & (critério de determinação da superfície livre) \\
\hline pnd_0 & 0.0 & $\begin{array}{l}\text { (constante da densidade do número de partículas caso } \\
\text { seja conhecido) }\end{array}$ \\
\hline wave_maker (amp_per) & 0.081 .6 & $\begin{array}{l}\text { (amplitude e período do movimento imposto ao tipo } \\
\text { wall_wm_type) }\end{array}$ \\
\hline
\end{tabular}

\subsection{Dados de Saída (Resultado da Simulação)}

Os dados contendo os resultados da simulação foram armazenados em um arquivo formato binário com as informações de número de partículas, instantes de tempo e os dados de cada partículas (tipo, posição, velocidade, pressão e densidade do número de partículas).

\subsection{Visualização}

Os resultados foram visualizados graficamente utilizando um programa baseado em OpenGL. O programa de visualização foi capaz de mostrar os diferents tipos de partículas (cada tipo de partícula possuía uma cor diferente), o vetor velocidade e a pressão de cada partícula em cada instante de tempo variando a intensidade da coloração. 


\section{DESCRIÇÃO DOS ENSAIOS NUMÉRICOS}

\subsection{Descrição do Equipamento Utilizado}

Para realizar as simulações numéricas foi utilizado um cluster de computadores do laboratório TPN (Tanque de Provas Numérico do departamento de engenharia naval e oceânica da Universidade de São Paulo) com 60 máquinas com a seguinte descrição:

- Motherboard - Intel GERG2LK

- Placa de rede Gigabit Ethernet on board

- Processador Intel Pentium 4 com clock de $2.4 \mathrm{GHz}$ com barramento de $533 \mathrm{MHz}$

- Memória DDR 333 de 512 Mbytes

- Hard Disk ATA 133 de 40 Gbytes

- Sistema Operacional Linux (Distribuição Gentoo)

A comunicação entre os nós foi feita por 3 switches Foundry Networks, modelo Edgeiron 24G.

\subsection{Validação do Método}

Nos artigos publicados sobre o método de partículas, na maioria delas, são feitas comparações visuais entre experiências físicas e simulações numéricas. No entanto, existe uma carência de comparações entre valores numéricos como a comparação de forças devido a ondas, por exemplo.

Para verificar a validade do método, foram realizados ensaios comparando as forças de excitação calculadas pelo método de partículas e pelo programa WAMIT (Wave Analisys $M I T)$. WAMIT é um programa baseado no método de painéis desenvolvido para análise 
de interações hidrodinâmicas entre corpos flutuantes ou submersos na presença de ondas amplamente utilizado na indústria e no meio acadêmico.

As geometrias e dimensões dos modelos utilizados pelo programa MPS são apresentados nas figs. 5.1 e 5.2. O primeiro modelo era composto por um tanque com um gerador de ondas de um lado e um absorvedor de ondas do outro lado. O segundo modelo era igual ao primeiro exceto pela presença de uma caixa no centro do tanque onde as forças de excitação foram medidas. Os dois modelos possuiam em torno de 130000 partículas.

Para cada período de onda foi necessário realizar simulações nos dois modelos descritos anteriormente. Isso se deve ao fato de serem modelos bidimensionais e é difícil medir as amplitudes e períodos das ondas geradas com a presença da caixa no centro. Então, foi feito a simulação no modelo sem caixa medindo as amplitudes em cada instante de tempo na mesma posição onde a caixa foi colocada e, em seguida, foi feito a mesma simulação com a presença da caixa medindo as forças de excitação.

O gerador de ondas movia-se horizontalmente com períodos entre 0.35 a 1.40 segundos.

As medições das forças de excitação foram feitas integrando as pressões levando em consideração o vetor normal de cada uma das partículas que envolvem a caixa (fig. 5.3).

O modelo utilizado no programa WAMIT para obter as forças de excitação é apresentado na fig. 5.4. O modelo tem comprimento de $1.0 \mathrm{~m}$, altura de $0.075 \mathrm{~m}$ e largura de $0.20 \mathrm{~m}$.

\subsection{Avaliação do Tempo Computacional}

Para avaliar as melhorias implementadas, foram realizadas simulações utilizando-se o método de partículas medindo o tempo consumido por funções que são responsáveis por boa parte do tempo total de cálculo. Foram realizados quatro conjuntos diferentes de ensaios.

No primeiro conjunto de ensaios foi avaliado a melhoria obtida com a otimização do cálculo da vizinhança.

O segundo, terceiro e quarto conjuntos de ensaios avaliaram a melhoria obtida com a 


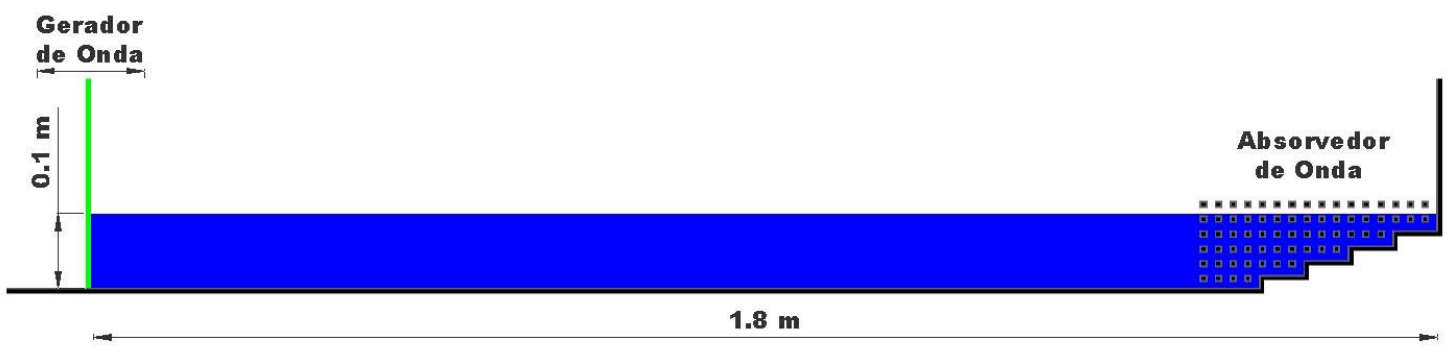

Figura 5.1 Dimensões do modelo de ensaio de validação sem caixa

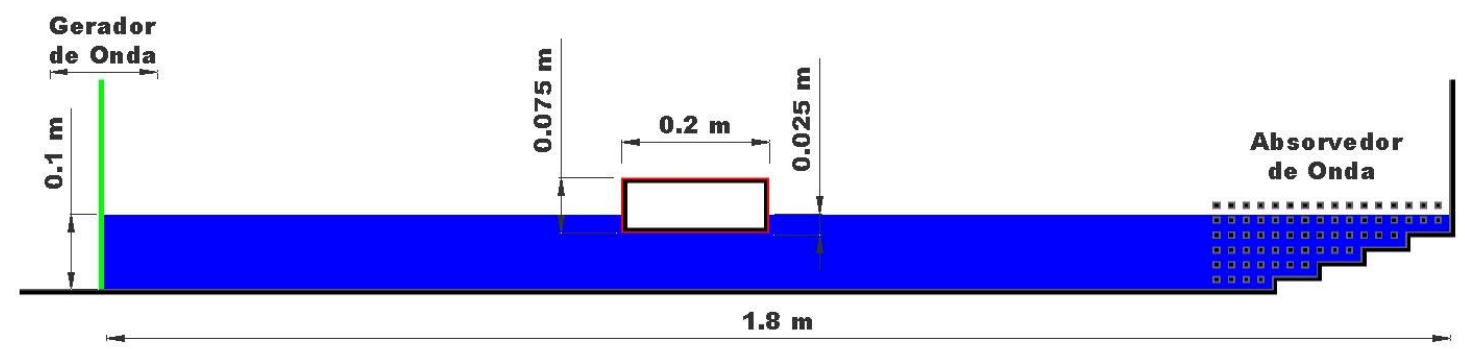

Figura 5.2 Dimensões do modelo de ensaio de validação com caixa

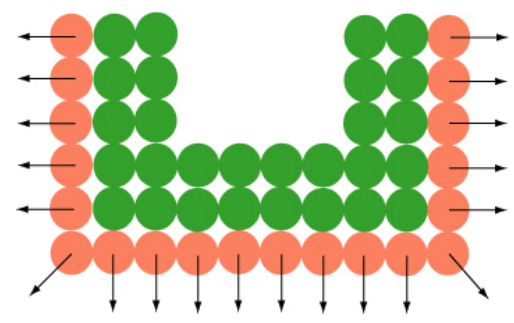

Figura 5.3 Representação simplificada da caixa e seus vetores normais

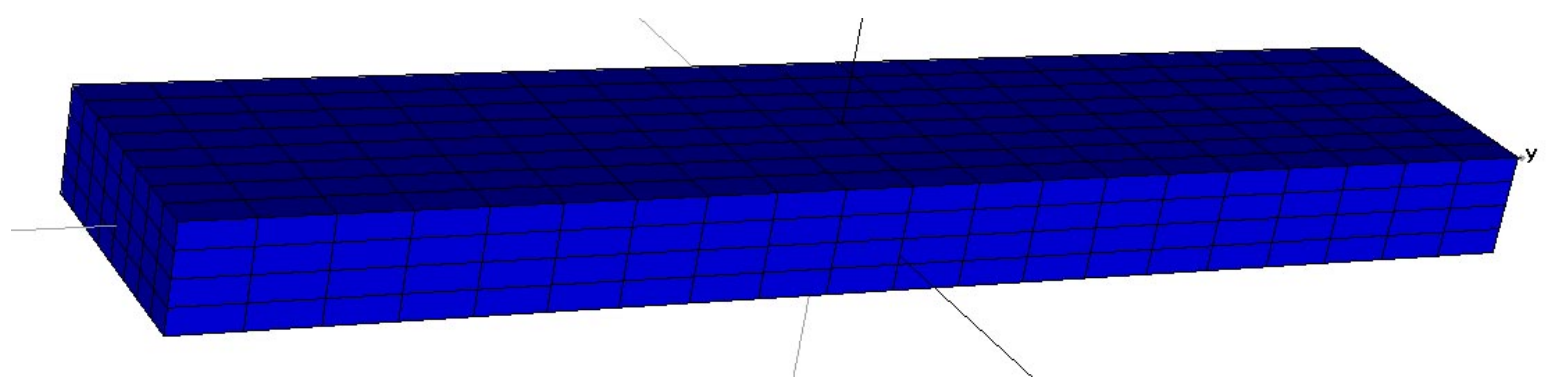

Figura 5.4 Modelo utilizado no programa WAMIT 
implementação do pacote PETSc em três aspectos diferentes.

No segundo conjunto foram testados diversos métodos que existem dentro do pacote PETSc que realizam a resolução do sistema linear de equações. Estes testes tem como objetivo determinar qual método de resolução se adequa melhor ao programa desenvolvido.

No terceiro conjunto foi medido a performance da resolução do sistema de equações (com o método de resolução que apresentou melhores resultados no segundo conjunto de ensaios) para diferentes número de processadores utilizados com diferentes números de partículas.

No quarto conjunto de testes foram medidos os tempos gastos por funções que variam de comportamento de acordo com o número de processadores utilizados.

O primeiro e o quarto conjunto de ensaios utilizaram os modelos semelhantes à fig. 5.5 com diferentes números de partículas $(780,1512,5868,10953,60891,102811,157849$, 184057,241370 e 416888 partículas).

O modelo utilizado para o segundo e terceiro conjuntos de ensaios foi o mesmo utilizado na validação do método mostrado na fig. 5.2 com 130177 partículas.

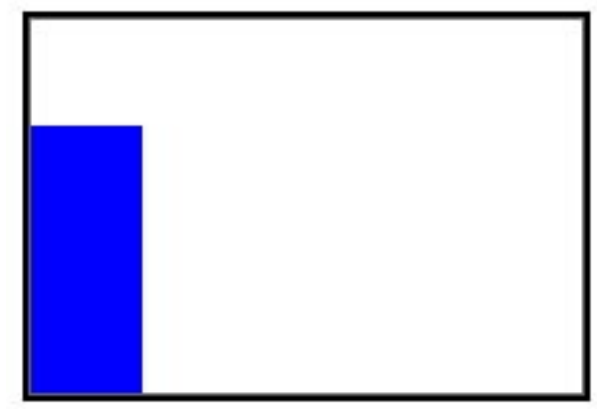

Figura 5.5 Exemplo de um dos modelos utilizado para avaliar o tempo computacional 


\section{RESULTADOS E DISCUSSÕES}

\subsection{Validação}

Os ensaio feitos para validar o método MPS descritos anteriormente na Seção 5.2 forneceu os resultados mostrados na tab. 6.1.

Os resultados obtidos no programa WAMIT estão apresentados na tab. 6.2.

Representando-os na forma de gráfico foram obtidos os gráficos mostrados nas figs. 6.1 e 6.2 comparando os resultados obtidos nos programas MPS e WAMIT para as forças de excitação na direção horizontal e vertical, respectivamente.

Algumas séries temporais de forças que foram tiradas das simulações de validação não puderam ser aproveitados principalmente nos casos em que os períodos de excitação eram muito baixos ou muito altos. Isso pode ter ocorrido devido à proximidade da caixa ao batedor de ondas e a forma como os modelos foram discretizados.

Considerando que o modelo criado para o MPS é bidimensional e o modelo do WAMIT tridimensional e o número de partículas utilizados poder ser insuficiente para gerar resultados mais precisos, os resultados obtidos da comparaçãodo entre MPS e WAMIT mostraram uma boa concordância entre eles. Os dois métodos seguem a mesma tendência para os diferentes períodos de onda e os valores de força estão próximos.

Ainda existe a necessidade de realizar outros testes de validação, porém, para o atual fase de desenvolvimento, os resultados até aqui mostraram-se satisfatórios.

\subsection{Avaliação do Tempo Computacional da Otimização do Cálculo da Vizinhança}

O ensaio feito para avaliar a otimização da função de cálculo da vizinhança descrito na Seção

5.3 forneceu os resultados mostrados na tab. 6.3 . 
Tabela 6.1 Amplitude de forças obtidas no programa MPS

\begin{tabular}{ccc}
\hline $\begin{array}{c}\text { Period } \\
(\mathrm{s})\end{array}$ & $\begin{array}{c}\text { Surge Force } \\
\text { Amplitude }\left(\frac{F}{\rho g A L}\right)\end{array}$ & $\begin{array}{c}\text { Heave Force } \\
\text { Amplitude }\left(\frac{F}{\rho g A L}\right)\end{array}$ \\
\hline \hline 0.35 & 0.047 & 0.045 \\
0.40 & 0.047 & 0.082 \\
0.45 & 0.044 & 0.091 \\
0.50 & 0.043 & 0.099 \\
0.60 & 0.043 & 0.110 \\
0.70 & 0.042 & 0.143 \\
0.80 & 0.042 & 0.134 \\
0.90 & 0.033 & 0.104 \\
1.00 & 0.036 & 0.122 \\
1.10 & 0.066 & 0.241 \\
1.20 & 0.059 & 0.351 \\
1.30 & 0.043 & 0.334 \\
1.40 & 0.023 & 0.183 \\
\hline
\end{tabular}

Tabela 6.2 Amplitude de forças obtidas no programa WAMIT

\begin{tabular}{ccc}
\hline $\begin{array}{c}\text { Periodo } \\
(\mathrm{s})\end{array}$ & $\begin{array}{c}\text { Amplitude da força } \\
\text { horizontal }\left(\frac{F}{\rho g A L}\right)\end{array}$ & $\begin{array}{c}\text { Amplitude da força } \\
\text { vertical }\left(\frac{F}{\rho g A L}\right)\end{array}$ \\
\hline \hline 0.1 & 0.005 & 0.002 \\
0.2 & 0.019 & 0.002 \\
0.3 & 0.030 & 0.026 \\
0.4 & 0.037 & 0.056 \\
0.5 & 0.042 & 0.089 \\
0.6 & 0.044 & 0.115 \\
0.7 & 0.044 & 0.132 \\
0.8 & 0.043 & 0.143 \\
0.9 & 0.041 & 0.153 \\
1.0 & 0.039 & 0.160 \\
1.1 & 0.037 & 0.166 \\
1.2 & 0.035 & 0.169 \\
1.3 & 0.033 & 0.172 \\
1.4 & 0.031 & 0.173 \\
1.5 & 0.030 & 0.173 \\
1.6 & 0.028 & 0.174 \\
1.7 & 0.027 & 0.174 \\
1.8 & 0.026 & 0.174 \\
1.9 & 0.024 & 0.174 \\
2.0 & 0.023 & 0.174 \\
\hline
\end{tabular}




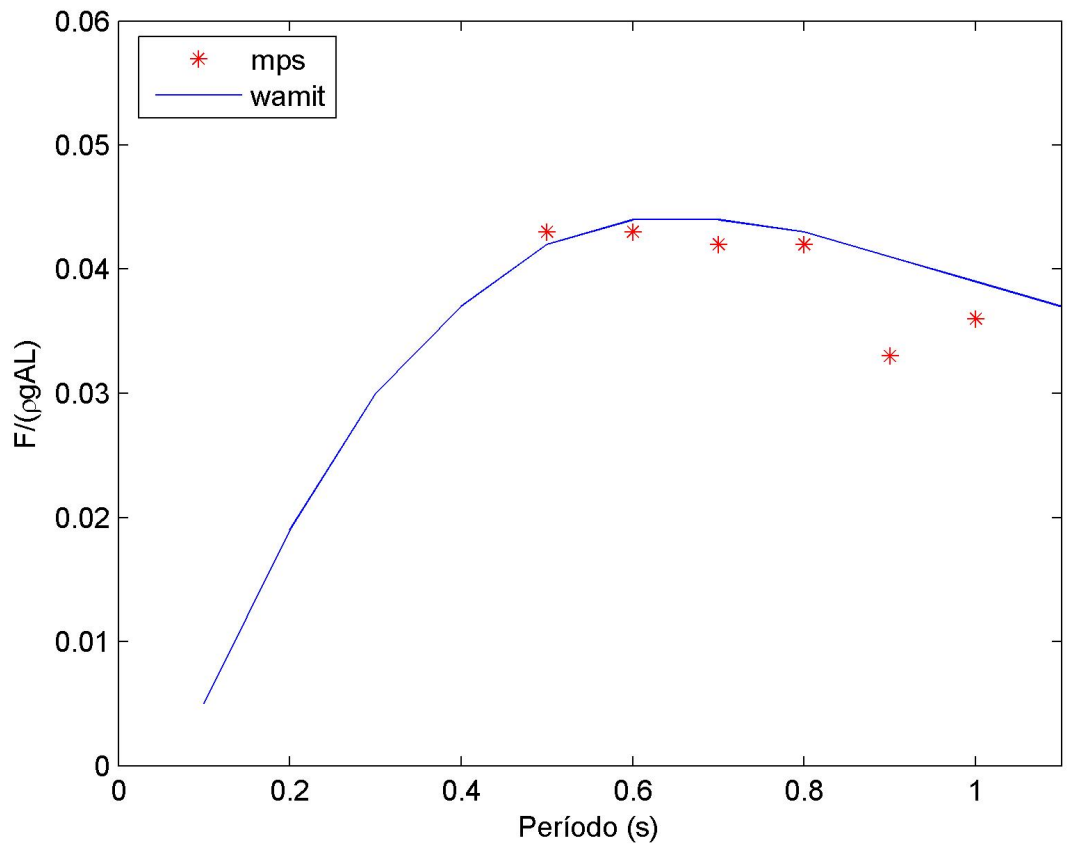

Figura 6.1 Amplitude de forças horizontais obtidas nos programas MPS e WAMIT

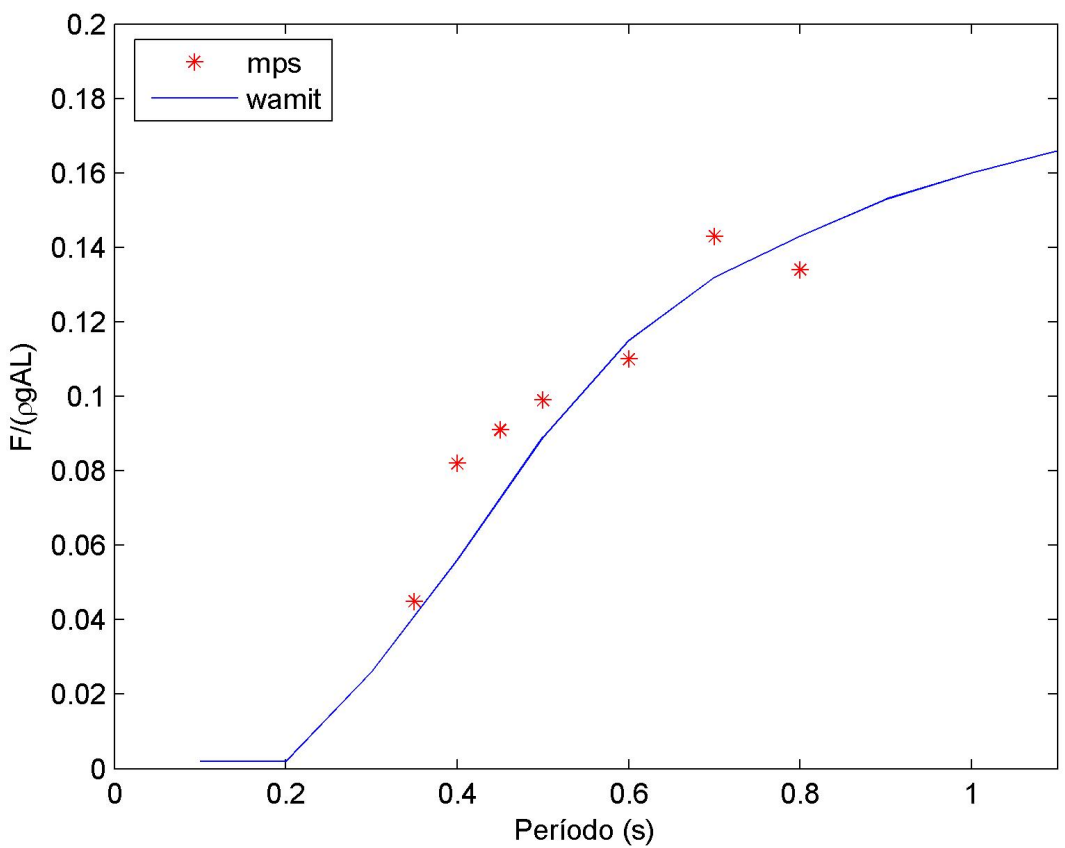

Figura 6.2 Amplitude de forças verticais obtidas nos programas MPS e WAMIT 
Figura 6.3 mostra esses resultados na forma de gráfico logarítmico comparando o tempo gasto no cálculo da vizinhança antes e depois da otimização.

Pôde-se observar pelo gráfico mostrado na fig. 6.3 que houve uma grande diminuição do tempo para o cálculo da vizinhança. Mesmo utilizando apenas um processador, passou a ser viável a simulação de modelos com mais de 50000 partículas. Simulações de 10 segundos que demoravam dias para serem calculados passaram a consumir algumas horas de cálculos.

Porém, a função que resolve o sistema de equações passou a ser o limitante quanto ao tamanho do problema que pode ser resolvido.

Tabela 6.3 Tempo gasto no cálculo da vizinhança

\begin{tabular}{ccc}
\hline $\begin{array}{c}\text { Número de } \\
\text { partículas }\end{array}$ & $\begin{array}{c}\text { Sem } \\
\text { otimização (s) }\end{array}$ & $\begin{array}{c}\text { Com } \\
\text { otimização (s) }\end{array}$ \\
\hline \hline 780 & 0.003 & 0.023 \\
1512 & 0.010 & 0.037 \\
5868 & 0.128 & 0.165 \\
10953 & 0.404 & 0.365 \\
60891 & 13.9 & 2.3 \\
102811 & 42.4 & 4.1 \\
157849 & 94.8 & 6.4 \\
184057 & 131.9 & 7.4 \\
241370 & 226.0 & 9.7 \\
416888 & 674.2 & 16.9 \\
\hline
\end{tabular}

\subsection{Avaliação do Tempo Computacional das Funções de Resolução do Sistema Linear Paralelizado do PETSc}

Os testes realizados para avaliar o método de resolução do sistema linear de equações que melhor se adequa ao programa de simulação forneceram os resultados apresentados na tab. 6.4 e a fig. 6.4 apresenta esses resultados na forma de gráfico. Tabela 6.4 mostra o tempo (em segundos) gasto por cada um dos métodos para diferentes quantidades de processadores. O valor entre parênteses é a relação entre o tempo gasto pelo método do PETSc e o tempo gasto pelo método ICCG (29.14s).

Observando os resultados de apenas um processador, todos os métodos testados 


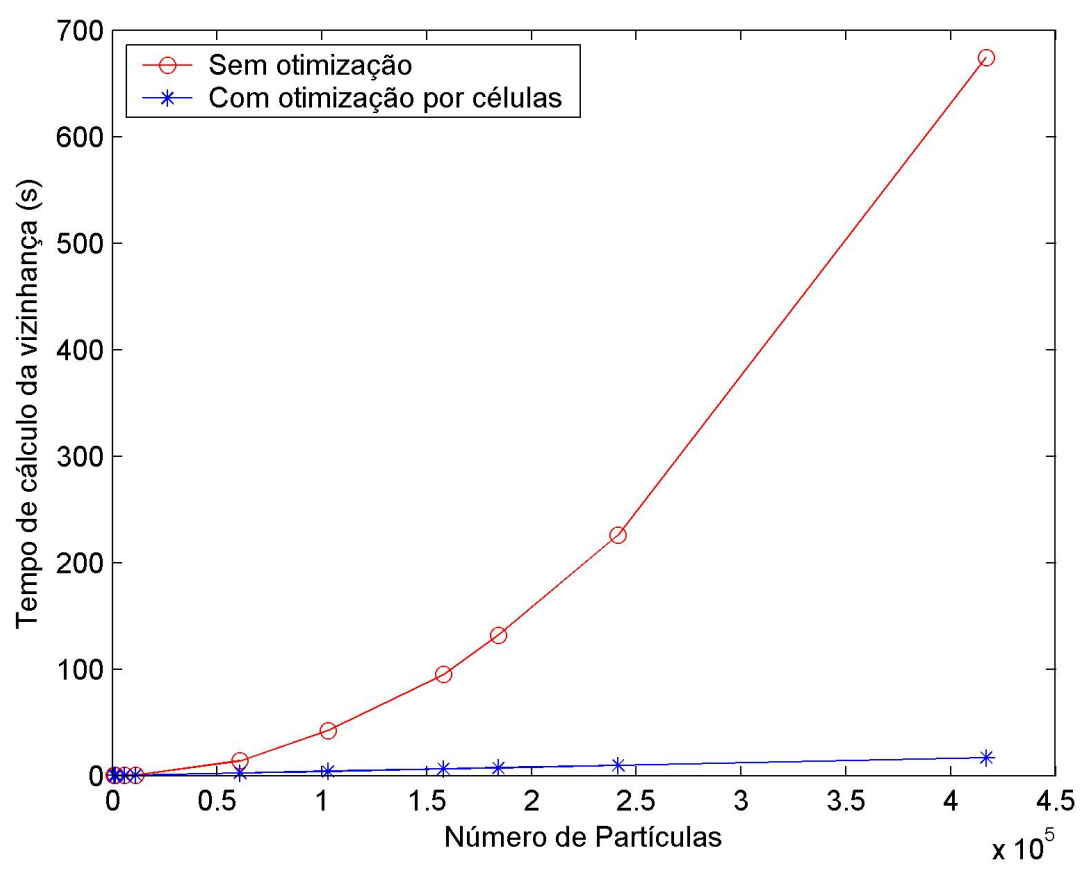

Figura 6.3 Tempo gasto no cálculo da vizinhança

tiveram um desempenho equivalente ou melhor que o método ICCG. Os métodos PCG, CR, MINRES, SYMMLQ e LGMRES além de consumir um menor tempo quando monoprocessado foram os métodos que tiveram melhor desempenho quando multiprocessados. Utilizando 16 processadores, esses métodos obtiveram uma economia de tempo de quase $90 \%$ em relação ao tempo gasto pelo método ICCG .

Entre esses 5 métodos foram observadas diferenças pequenas de economia de tempo. Como o método PCG teve um desempenho geral melhor que os outros, ele foi selecionado para resolver o sistema linear de equações das análises seguintes.

Tabela 6.4 Tempo gasto na resolução do sistema linear de um passo de tempo para diferentes números de processadores (130177 partículas)

\begin{tabular}{ccccccccccc}
\hline $\mathrm{N}$ & GMFRES(s) & PCG(s) & BCGS(s) & BCGSL(s) & TFQMR(s) & CR(s) & BICG(s) & MINRES(s) & SYMMLQ(s) & LGMRES(s) \\
\hline \hline 1 & $30.48(1.22)$ & $18.11(0.62)$ & $24.52(0.84)$ & $30.43(1.04)$ & $23.69(0.81)$ & $18.45(0.63)$ & $36.02(1.24)$ & $20.56(0.71)$ & $21.78(0.75)$ & $21.89(0.75)$ \\
2 & $21.63(1.12)$ & $15.94(0.55)$ & $23.72(0.81)$ & $23.89(0.82)$ & $24.94(0.86)$ & $16.15(0.55)$ & $28.8(0.99)$ & $17.35(0.60)$ & $18.63(0.64)$ & $18.68(0.64)$ \\
4 & $11.11(0.55)$ & $7.96(0.27)$ & $11.71(0.40)$ & $12.6(0.43)$ & $11.54(0.40)$ & $8.01(0.27)$ & $15.82(0.54)$ & $8.57(0.29)$ & $8.9(0.31)$ & $8.64(0.30)$ \\
8 & $6.54(0.40)$ & $4.76(0.16)$ & $7.61(0.26)$ & $9.45(0.32)$ & $9.84(0.34)$ & $5.8(0.20)$ & $8.65(0.30)$ & $5.6(0.19)$ & $7.22(0.25)$ & $6.36(0.22)$ \\
16 & $5.9(0.26)$ & $3.29(0.11)$ & $4.94(0.17)$ & $5.27(0.18)$ & $4.82(0.17)$ & $3.54(0.12)$ & $6.09(0.21)$ & $3.2(0.11)$ & $3.47(0.12)$ & $3.54(0.12)$ \\
32 & $8.57(0.44)$ & $6.31(0.22)$ & $9.41(0.32)$ & $9.51(0.33)$ & $7.82(0.27)$ & $5.77(0.20)$ & $7.54(0.26)$ & $6.59(0.23)$ & $6.46(0.22)$ & $5.78(0.20)$ \\
60 & $10.98(0.61)$ & $7.01(0.24)$ & $8.46(0.29)$ & $9.28(0.32)$ & $7.16(0.25)$ & $6.97(0.24)$ & $9.77(0.34)$ & $6.01(0.21)$ & $8.83(0.30)$ & $5.14(0.18)$ \\
\hline
\end{tabular}




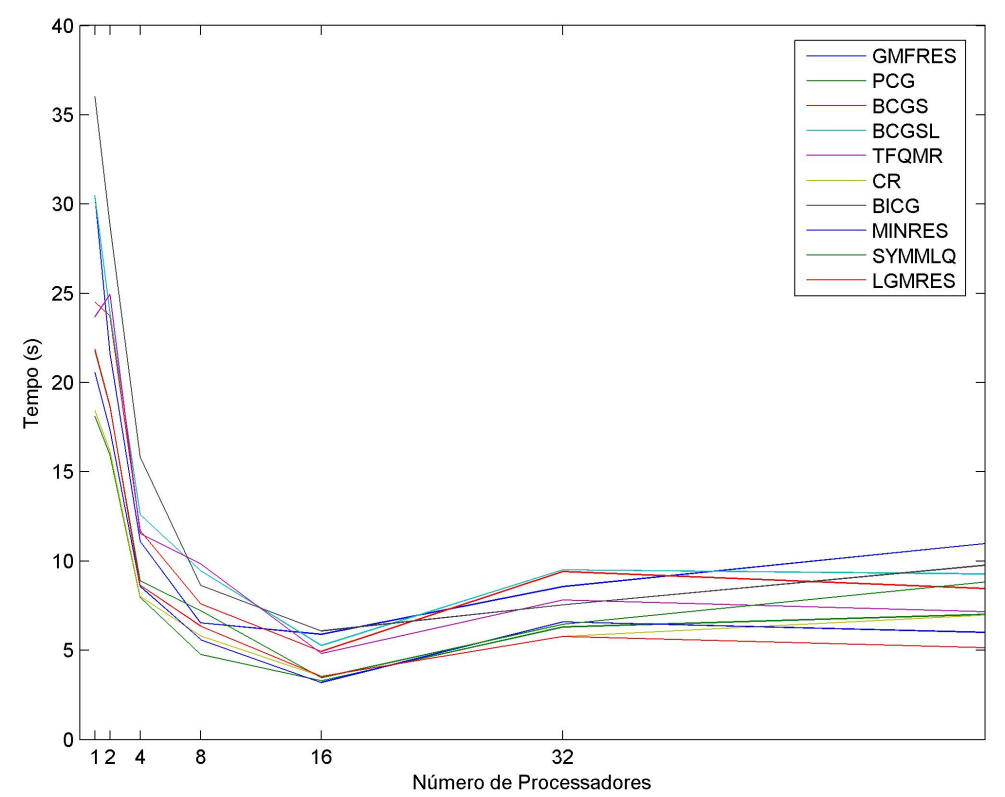

Figura 6.4 Tempo gasto na resolução do sistema linear de um passo de tempo para diferentes números de processadores (130177 partículas)

\subsection{Avaliação do Tempo Computacional da Resolução do Sistema Linear Paralelizado}

Os ensaios feitos para medir o ganho de performance da função que resolve o sistema linear de equações apresentados na Seção 5.3 forneceram os resultados mostrados na tab. 6.5.

Figura 6.5 mostra esses resultados na forma de gráfico comparando o desempenho para diferentes números de partículas.

Pelo gráfico mostrado na fig. 6.5, no caso com 10953 partículas não houve diminuição do tempo gasto na função que soluciona o sistema linear com o acréscimo do número de nós utilizados.

Já a partir do caso com 60981 partículas ficou evidente a economia de tempo computacional. Quanto maior o número de partículas utilizados no modelo, maior foi a diferença de desempenho quando foi comparado o cálculo foi feito em um nó ou em vários nós.

Vale destacar que existe uma quantidade de nós ideal para diferentes números de 
partículas que formam o modelo de simulação. Por isso, não faz sentido utilizar todos os processadores disponíveis para qualquer modelo.

Tabela 6.5 Tempo gasto na resolução do sistema linear para diferentes números de processadores

com diferentes números de partículas

\begin{tabular}{ccccccc}
\hline $\begin{array}{c}\text { Número de } \\
\text { processadores }\end{array}$ & $\begin{array}{c}10953 \\
\text { partículas (s) }\end{array}$ & $\begin{array}{c}60981 \\
\text { partículas (s) }\end{array}$ & $\begin{array}{c}102812 \\
\text { partículas (s) }\end{array}$ & $\begin{array}{c}157849 \\
\text { partículas (s) }\end{array}$ & $\begin{array}{c}241370 \\
\text { partículas (s) }\end{array}$ & $\begin{array}{c}416888 \\
\text { partículas (s) }\end{array}$ \\
\hline \hline 1 & 0.40 & 5.69 & 12.83 & 27.25 & 50.82 & 152.48 \\
2 & 0.44 & 4.07 & 8.58 & 19.87 & 43.40 & 100.67 \\
4 & 0.34 & 2.24 & 4.77 & 9.87 & 18.38 & 49.94 \\
8 & 0.40 & 1.29 & 3.08 & 5.88 & 10.42 & 22.39 \\
16 & 0.89 & 1.14 & 2.14 & 3.78 & 7.01 & 13.90 \\
32 & 1.48 & 1.70 & 3.01 & 4.57 & 5.68 & 11.16 \\
60 & 2.71 & 4.91 & 7.81 & 9.80 & 10.24 & \\
\hline
\end{tabular}

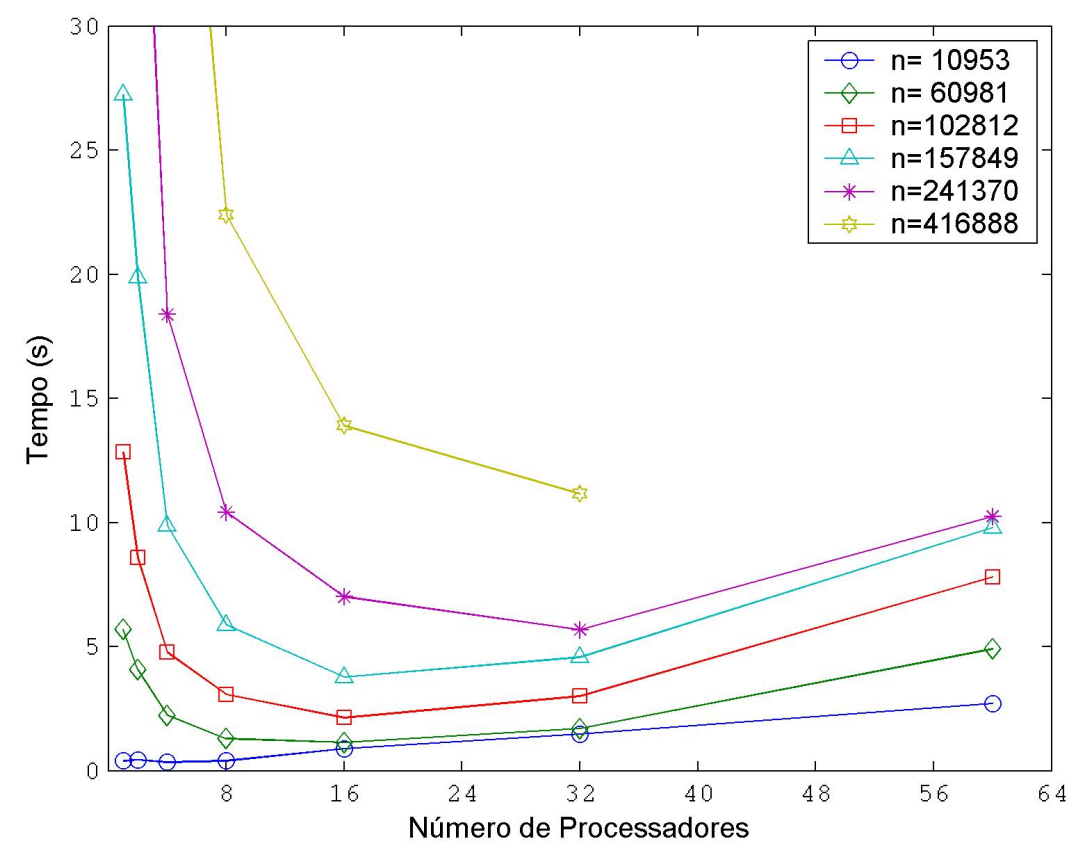

Figura 6.5 Tempo gasto na resolução do sistema linear para diferentes número de processadores com diferentes números de partículas

\subsection{Avaliação do Tempo Computacional das Funções Paralelizadas}

Os ensaios feitos para verificar o comportamento de funções paralelizadas apresentadas na Seção 5.3 forneceu os resultados mostrados na tab. 6.6. 
Figura 6.6 mostra comparações do tempo computacional de cada função para diferentes números de partículas.

Pôde-se observar no gráfico da fig. 6.6 que o tempo gasto para resolução do sistema linear diminuiu bastante aumentando-se o número de processadores utilizados; com 16 nós, a função mostra seu melhor desempenho. A partir de 16 nós, o tempo gasto com a comunicação entre os nós passa a diminuir a eficiência.

Porém, quando utilizou-se o pacote PETSc, não deve-se limitar a analisar apenas a função comentada acima pois funções como de criação da matriz e de união dos resultados de pressão espalhados pelos nós em um único vetor do nó principal dependem do número de nós utilizados também.

O tempo gasto por essas duas funções apenas cresceu com o número de nós.

Analisando o tempo total gasto por essas três funções, pôde-se perceber um desempenho melhor para este caso calculando-o com 8 a 16 nós.

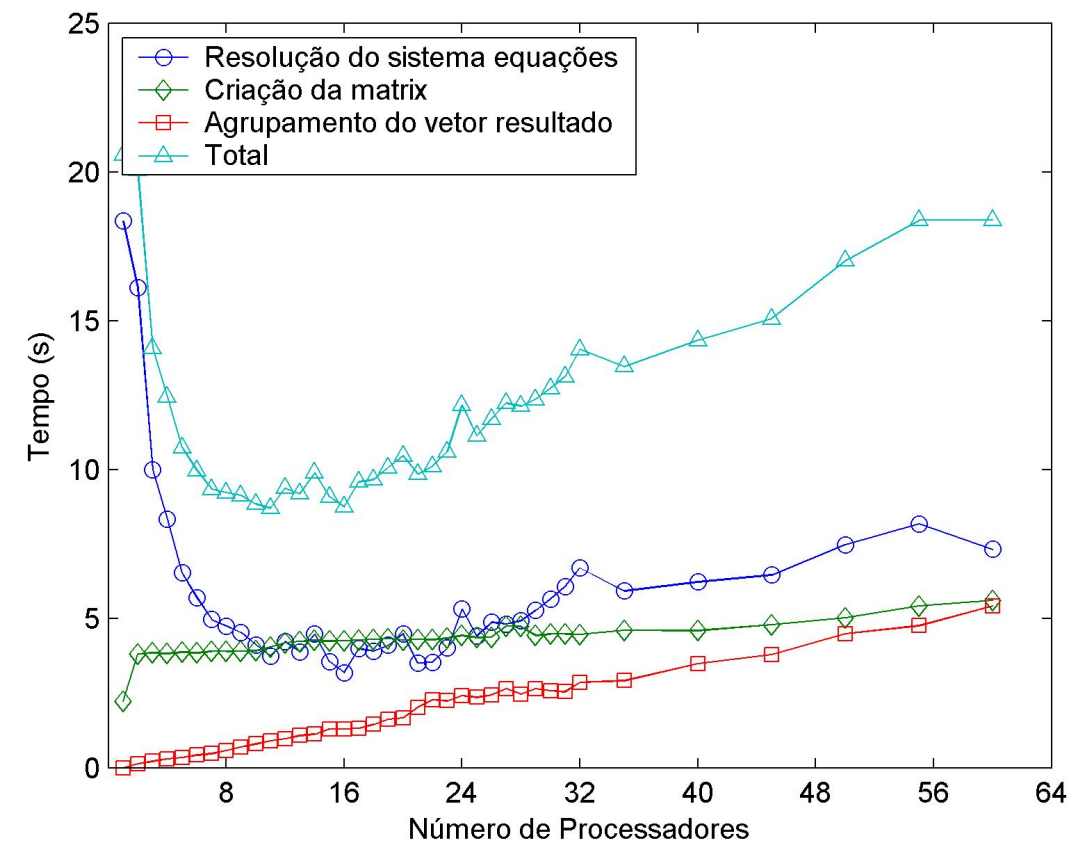

Figura 6.6 Tempo gasto por funções paralelizadas 
Tabela 6.6 Tempo gasto por funções paralelizadas

\begin{tabular}{|c|c|c|c|c|}
\hline $\begin{array}{l}\text { Número de } \\
\text { partículas }\end{array}$ & $\begin{array}{c}\text { Resolução do sistema } \\
\text { de equações (s) }\end{array}$ & $\begin{array}{l}\text { Criação da } \\
\text { matriz (s) }\end{array}$ & $\begin{array}{l}\text { Agrupamento do vetor } \\
\text { de resultados (s) }\end{array}$ & $\begin{array}{c}\text { Total } \\
\text { (s) }\end{array}$ \\
\hline 1 & 18.36 & 2.22 & 0.00 & 20.58 \\
\hline 2 & 16.12 & 3.82 & 0.13 & 20.06 \\
\hline 3 & 10.01 & 3.86 & 0.22 & 14.09 \\
\hline 4 & 8.34 & 3.83 & 0.30 & 12.46 \\
\hline 5 & 6.54 & 3.88 & 0.35 & 10.76 \\
\hline 6 & 5.71 & 3.86 & 0.43 & 9.99 \\
\hline 7 & 4.98 & 3.90 & 0.47 & 9.35 \\
\hline 8 & 4.76 & 3.90 & 0.58 & 9.24 \\
\hline 9 & 4.54 & 3.92 & 0.70 & 9.15 \\
\hline 10 & 4.13 & 3.93 & 0.80 & 8.85 \\
\hline 11 & 3.75 & 4.06 & 0.91 & 8.71 \\
\hline 12 & 4.23 & 4.19 & 0.97 & 9.39 \\
\hline 13 & 3.89 & 4.24 & 1.08 & 9.20 \\
\hline 14 & 4.49 & 4.28 & 1.13 & 9.90 \\
\hline 15 & 3.56 & 4.25 & 1.30 & 9.10 \\
\hline 16 & 3.19 & 4.27 & 1.30 & 8.76 \\
\hline 17 & 4.00 & 4.29 & 1.32 & 9.60 \\
\hline 18 & 3.91 & 4.31 & 1.45 & 9.67 \\
\hline 19 & 4.11 & 4.34 & 1.63 & 10.07 \\
\hline 20 & 4.50 & 4.29 & 1.68 & 10.47 \\
\hline 21 & 3.52 & 4.31 & 2.03 & 9.86 \\
\hline 22 & 3.54 & 4.30 & 2.28 & 10.12 \\
\hline 23 & 4.02 & 4.35 & 2.25 & 10.61 \\
\hline 24 & 5.33 & 4.44 & 2.42 & 12.18 \\
\hline 25 & 4.42 & 4.37 & 2.36 & 11.14 \\
\hline 26 & 4.88 & 4.38 & 2.45 & 11.71 \\
\hline 27 & 4.83 & 4.76 & 2.65 & 12.24 \\
\hline 28 & 4.93 & 4.74 & 2.47 & 12.14 \\
\hline 29 & 5.28 & 4.44 & 2.65 & 12.36 \\
\hline 30 & 5.67 & 4.49 & 2.58 & 12.74 \\
\hline 31 & 6.09 & 4.49 & 2.55 & 13.13 \\
\hline 32 & 6.71 & 4.48 & 2.86 & 14.05 \\
\hline 35 & 5.93 & 4.62 & 2.92 & 13.47 \\
\hline 40 & 6.24 & 4.61 & 3.50 & 14.35 \\
\hline 45 & 6.47 & 4.80 & 3.80 & 15.07 \\
\hline 50 & 7.49 & 5.04 & 4.50 & 17.02 \\
\hline 55 & 8.19 & 5.43 & 4.77 & 18.38 \\
\hline 60 & 7.34 & 5.62 & 5.43 & 18.38 \\
\hline
\end{tabular}




\subsection{Exemplos}

Foram criado diversos modelos para testar a estabilidade do programa e avaliar o realismo dos resultados gerados. Figuras 6.7 e 6.8 mostram dois exemplos de testes realizados.

Os exemplos mostraram comportamentos bastante realistas com destaque aos efeitos altamente não-lineares como quebra de onda e fregmentação de fluido.
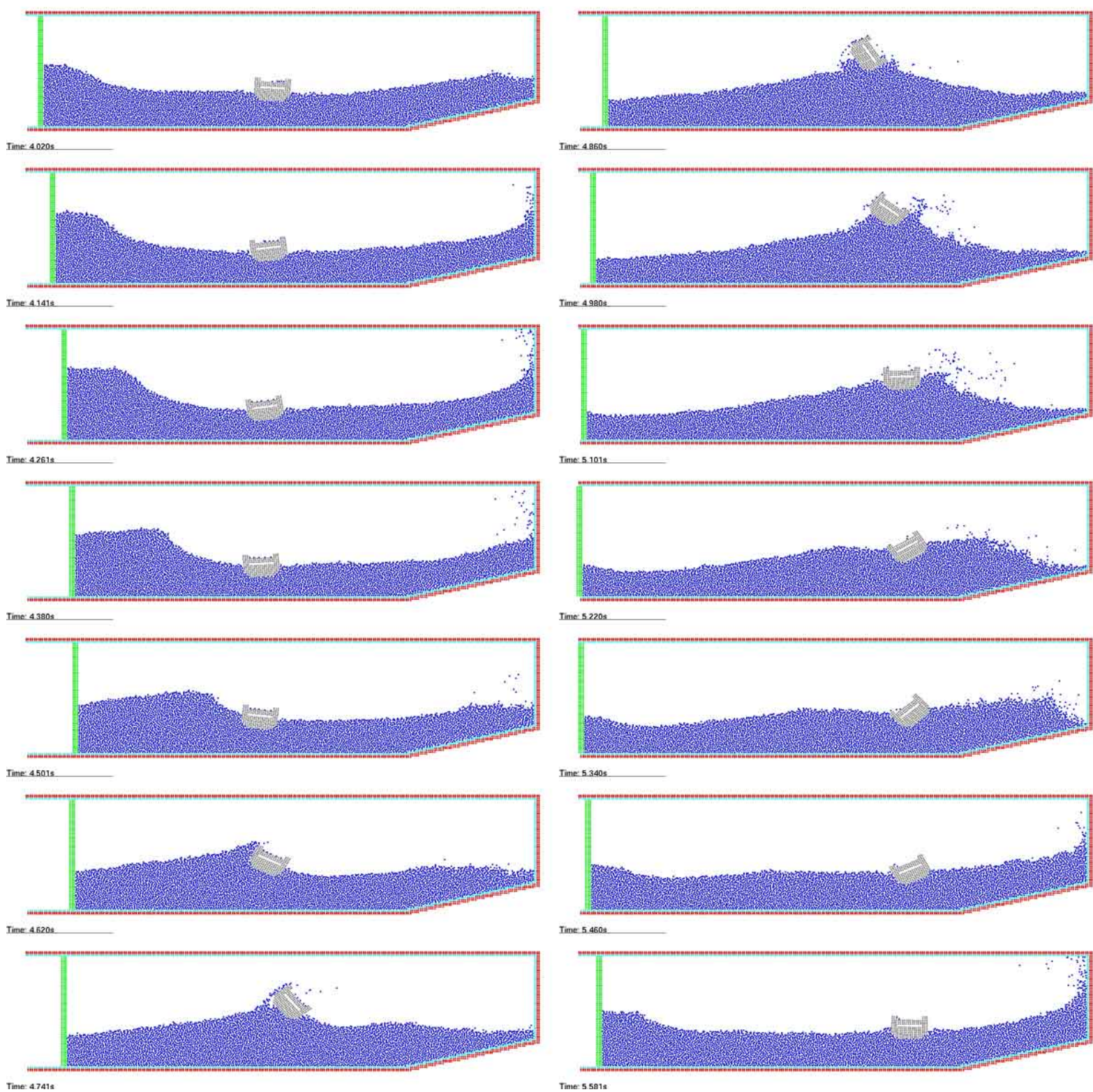

Figura 6.7 Caso exemplo com 7024 partículas 

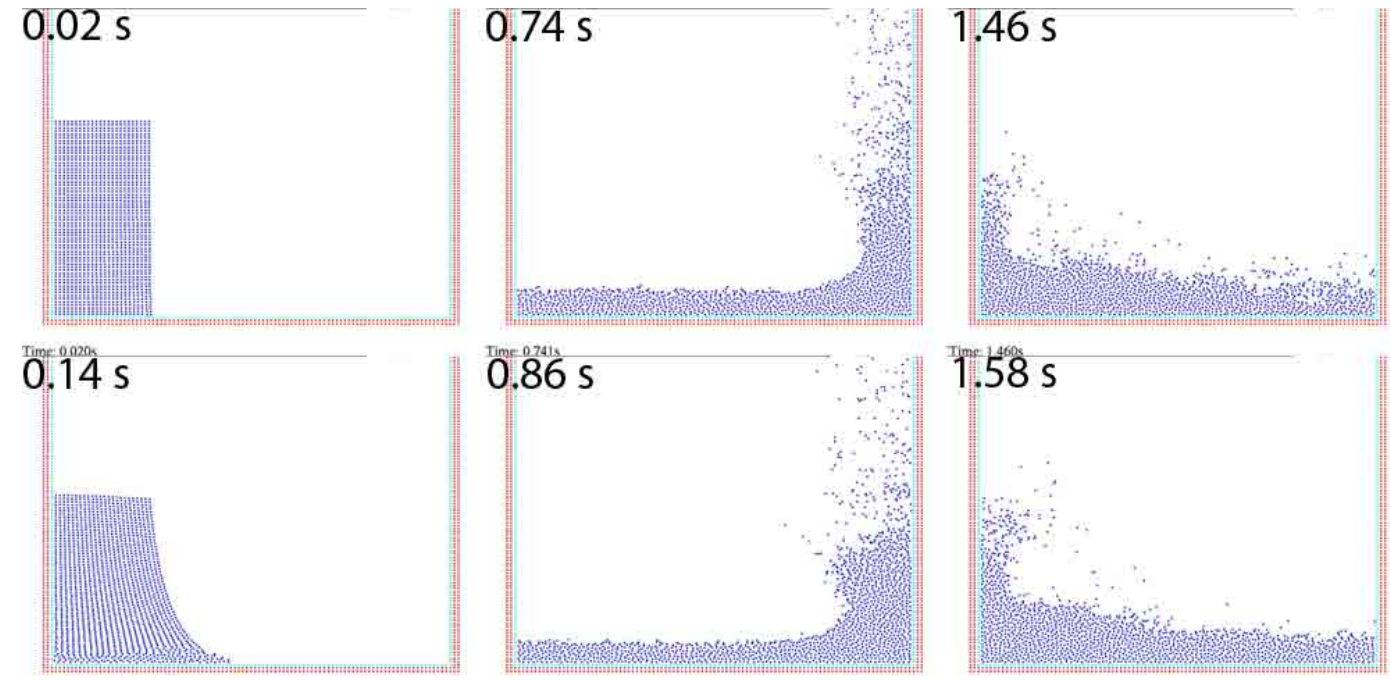

$0.86 \mathrm{~s}$
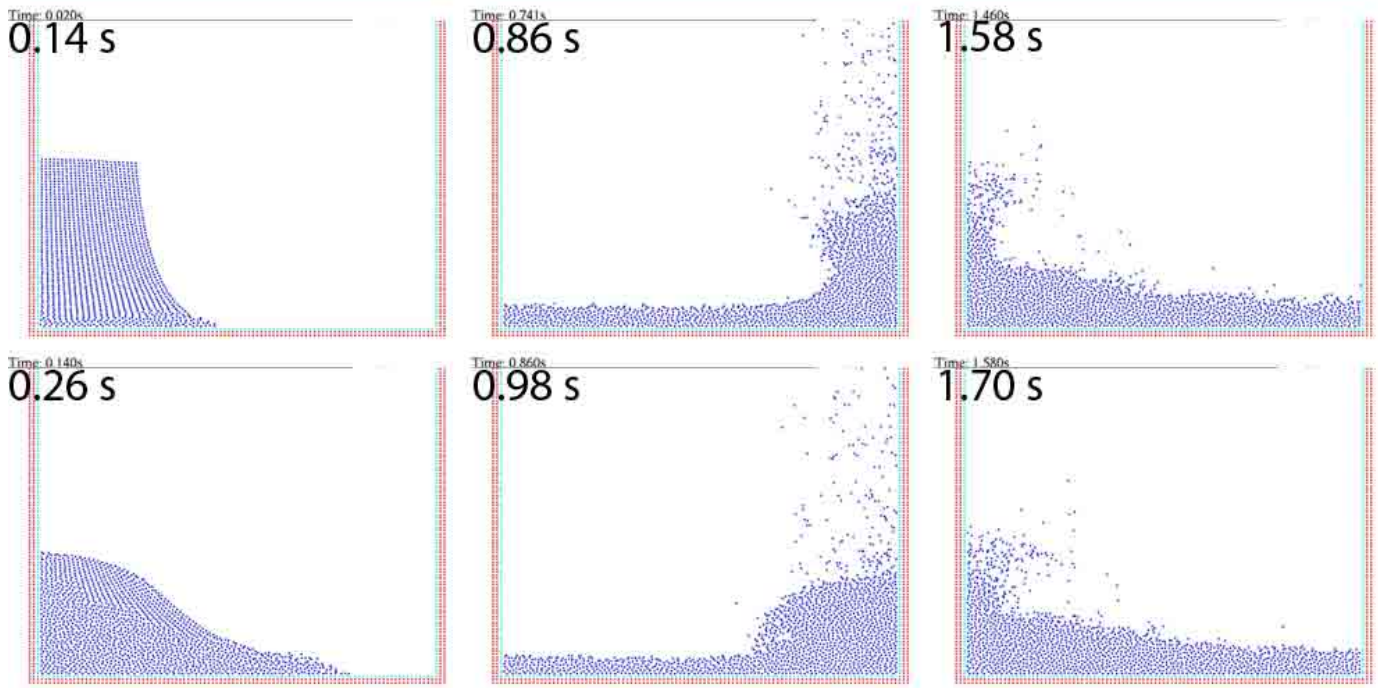

$0.98 \mathrm{~s}$

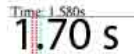

$0.38 \mathrm{~s}$

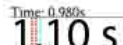

$1.82 \mathrm{~s}$
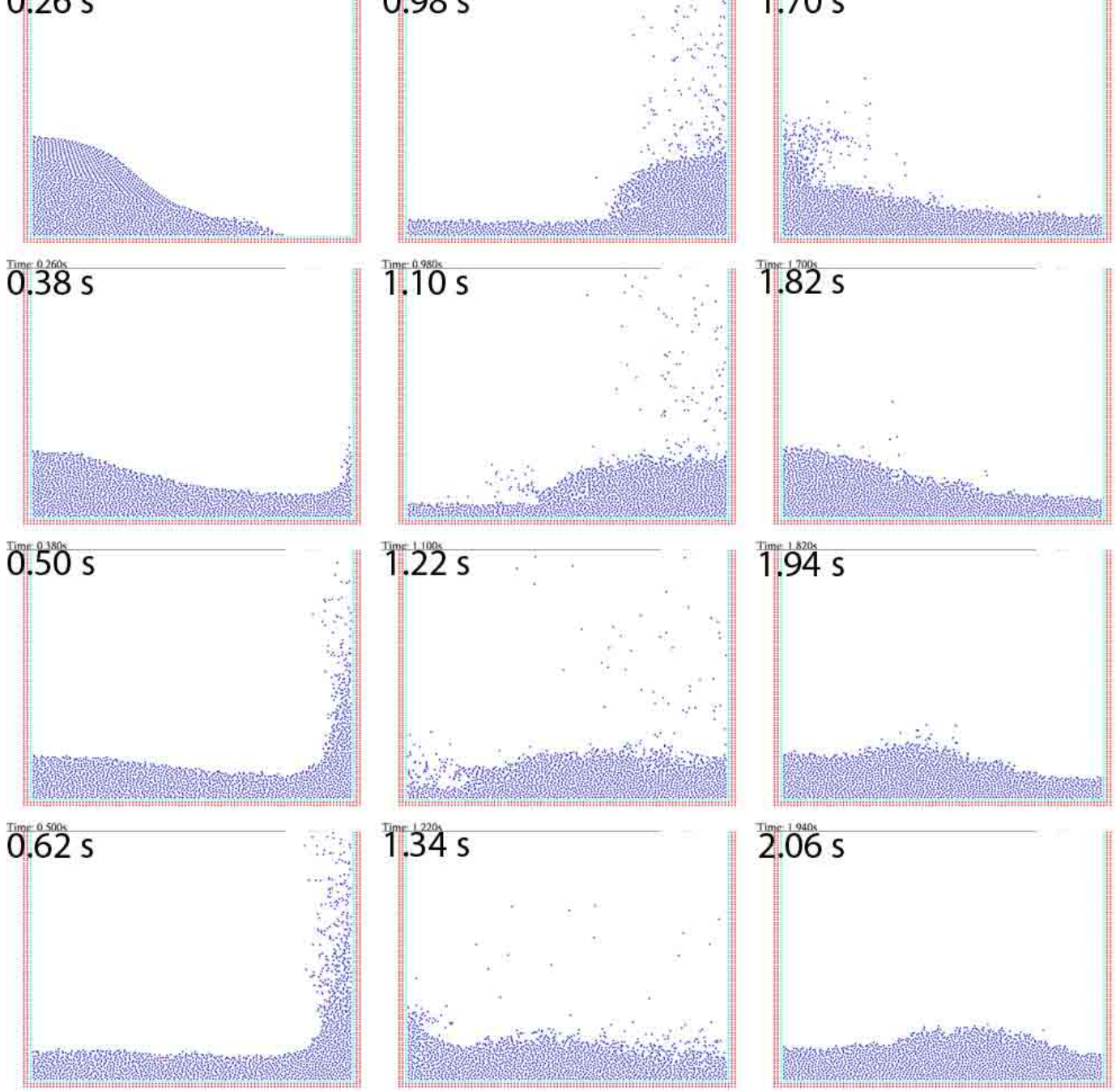

Figura 6.8 Caso exemplo com 3078 partículas 


\subsection{Avaliação do número de partículas necessários}

Um problema comum em dinâmica de fluidos computacional é saber o quanto um modelo precisa ser discretizado para que gere resultados confiáveis.

Gerando diversas simulações utilizando o método de partículas MPS, foi constatado que as simulações ficam mais realistas visualmente quando o modelo tem uma discretização maior. Porém, nenhuma comparação com valores numéricos foi feita para avaliar modelos com diferentes quantidades de partículas.

Um procedimento que pode ser seguido para realizar esta avaliação é criar modelos com dimensões iguais mas com número de partículas diferentes e calcular seu comportamento. Em seguida, compara-se os resultados desses modelos e caso as diferenças estejam dentro de determinados valores aceitáveis o modelo de menor discretização pode ser utilizado para a simulação. Caso as diferenças de resultados sejam maiores que a precisão desejada, é necessário criar um outro modelo mais discretizado e seguir o mesmo procedimento até chegar a precisão desejada. 


\section{CONCLUSÕES}

Os resultados obtidos pelos programas MPS e WAMIT quando comparados tiveram uma boa aderência. O que mostra que o desenvolvimento do programa está no caminho certo. Porém, ainda não é possível afirmar que o programa está totalmente validado. Existe ainda a necessidade de comparar modelos tridimensionais com experimentos reais ou outros métodos para diferentes tipos de fenômenos.

Para fins qualitativos, o método já é de grande utilidade para analisar fenômenos fluidos difíceis de prever por meios tradicionais.

A otimização feita no cálculo da vizinhança apresentou resultados bastante satisfatórios devido ao grande ganho de desempenho que foi obtido.

A utilização do pacote PETSc possibilitou a diminuição do tempo para resolução do sistema linear de equações, principalmente nos casos com número elevado de partículas.

A melhora de performance obtida ainda está aquém do que é necessário para fazer o programa utilizável em aplicações científicas ou industriais (principalmente em simulações tridimensionais onde o número de partículas necessário para descrever o modelo cresce consideravelmente).

Com a paralelização da função que resolve o sistema linear, o cálculo de vizinhança voltou a ser o gargalo do programa.

É necessário diminuir ainda mais o tempo computacional. Algumas das possibilidade de otimização do código são a paralelização do cálculo de vizinhança e paralelização do domínio.

Na literatura o método já se mostrou com um grande potencial para diversas aplicações. O programa desenvolvido durante este estudo já reproduz vários dos resultados obtidos por outros pesquisadores e mostrou ser uma poderosa ferramenta de análise de dinâmica de fluidos. 


\section{TRABALHOS FUTUROS}

- Pesquisar novas técnicas de otimização.

- Fazer o programa ser capaz de simular modelos tridimensionais.

- Continuar validação do programa para diversos tipos de fenômenos fluidos. 


\section{REFERÊNCIAS}

Baker, A. H., Jessup, E., and Manteuffel, T.(2005). A technique for accelerating the convergence of restarted gmres. SIAM Journal on Matrix Analysis and Applications, 26:962-984.

Balay, S., Buschelman, K., Gropp, W. D., Kaushik, D., Knepley, M. G., McInnes, L. C., Smith, B. F., and Zhang, H.(2001). PETSc Web page. http: / / www . mcs . anl . gov/petsc.

Benz, W.(1990). Smooth Particle Hydrodynamics: A Review. Kluwer Academic Publishers, The Netherlands.

Brackbill, J. U.(1988). The ringing instability in particle-in-cell calculations of low-speed flow. Journal of Computational Physics, 75(2):469-492.

Brackbill, J. U., Kothe, D. B., and Ruppel, H. M.(1988). Flip: A low-dissipation, particle-in-cell method for fluid flow. Computer Physics Communications, 48:25-38.

Brackbill, J. U. and Ruppel, H. M.(1986). Flip: A method for adaptively zoned, particle-in-cell calculations of fluid flows in two dimensions. Journal of Computational Physics, 65:314343.

Chikazawa, Y., Koshizuka, S., and Oka, Y.(1998). Numerical calculation of sloshing in a tank with elastic walls using a particle method. In $6^{\text {th }}$ International Conference on Nuclear Engineering. ICONE-6, ASME.

Chikazawa, Y., Koshizuka, S., and Oka, Y.(2001). A particle method for elastic and viscoplastic structures and fluid-structure interactions. Computational Mechanics, 27:97-106.

Daly, B. J., Harlow, F. H., Welch, J. E., Wilson, E. N., and Sanmann, E. E.(1965). Numerical fluid dynamics using the particle-and-force method. LA3144. 
Duan, R.-Q., Koshizuka, S., and Oka, Y.(2003). Two-dimensional simulation of drop deformation and breakup at around the critical weber number. Nuclear Engineering and Design, 225:37-48.

Faber, V. and Manteuffel, T.(1984). Necessary and sufficient conditions for the existence of a conjugate gradient method. SIAM Journal on Numerical Analysis, 21:315-339.

Gingold, R. A. and Monaghan, J. J.(1982). Kernel estimates as a basis for general particle methods in hydrodynamics. Journal of Computational Physics, 46:429-453.

Gupta, A.(2001). WSMP Home Page. http: //www-users. cs . umn . edu/ agupta/wsmp. html.

Harlow, F. H. and Welch, J. E.(1988). Numerical calculation of time-dependent viscous incompressible flow of fluid with free surface. Physics of Fluids, 8:2182.

Hayama, S., Ariga, K., and Watanabe, T.(1983). . Transactions of the Japan Society of Mechanical Engineers C, 22:437.

Henneken, E. A. C. and Icke, V.(1993). Sph faces emery's jump. Computer Physics Communications, 74:239-246.

Heo, S., Koshizuka, S., and Oka, Y.(2002). Numerical analysis of boiling on high heat-flux and high subcooling condition using mps-mafl. International Journal of Heat and Mass Transfer, 45:2633-2642.

Ikeda, H., Koshizuka, S., and Oka, Y.(1999). Numerical analysis of water jet dynamics in coolant injection mode of fuel-coolant interactions. In $7^{\text {th }}$ International Conference on Nuclear Engineering, Tokyo, Japan. ICONE-7113, JSME.

Intel(2004). Math Kernel Library 7.2. http: / / www. intel . com/software/products/mkl/.

Koshizuka, S., Nobe, A., and Oka, Y.(1998a). Numerical analysis of breaking waves using the moving particle semi-implicit method. International Journal for Numerical Methods in Fluids, 26:751-769. 
Koshizuka, S., Ohta, K., and Oka, Y.(1998b). Development of a 3D calculation scheme using moving particle semi-implicit method for thermal hydraulics. In $\sigma^{\text {th }}$ International Conference on Nuclear Engineering. ICONE-6225, ASME.

Koshizuka, S. and Oka, Y.(1996). Moving-particle semi-implicit method for fragmentation of incompressible fluid. Nuclear Science and Engineering, 123:421-434.

Koshizuka, S. and Oka, Y.(1997). A particle method for complex fluid dynamics with interfaces. In JSME Centennial Grand Congress, International Conference on Fluid Engineering, Tokyo, Japan. The Japan Society of Mechanical Engineers, JSME.

Koshizuka, S., Tamako, H., and Oka, Y.(1995). A paricle method for incompressible viscous flow with fluid fragmentation. Journal Computational Fluid Dynamics, 62:29-46.

Libersky, L. D., Petscheck, A. G., Carney, T. C., Hipp, J. R., and Allahdadi, F. A.(1993). High strain lagrangian hydrodynamics - a three-dimensional sph code for dynamic material response. Journal of Computational Physics, 109:67-75.

Liu, J., Koshizuka, S., and Oka, Y.(2004). A hybrid particle-mesh method for viscous, incompressible, multiphase flows. Journal of Computational Physics, 202:65-93.

Liu, J., Koshizuka, S., and Oka, Y.(2005). Evaluation of the energy conversion ratio of vapor explosions for the assessment of nuclear reactor safety. Journal of Nuclear Science and Technology, 42(1):28-39.

Martin, J. C. and Moyce, W. J.(1952). An experimental study of the collapse of liquid column on a rigid horizontal plane. Philosophical Transactions Royal Society London A, 244:312.

Monaghan, J. J.(1988). An intrtoduction to sph. Computer Physics Communications, 48:89-96.

Monaghan, J. J. and Gingold, R. A.(1983). Shock simulation by the particle method sph. Journal of Computational Physics, 52:374-389.

Naito, S. and Sueyoshi, M.(2002a). A numerical analysis of violent free surface by particle method. In The Proceedings of The Fifth (2002) ISOPE Pacific/Asia Offshore Mechanics Symposium, page 219, Daejeon, Korea. International Society of Offshore and Polar Engineers (ISOPE). 
Naito, S. and Sueyoshi, M.(2002b). A numerical study on complicated motions of floating bodies. In Sixth International Ship Stability Workshop, Glen Cove, New York. Webb Institute.

Paige, C. and Saunders, M.(1975). Solution of sparse indefinite systems of linear equations. SIAM Journal on Numerical Analysis, 12:617-629.

Poliakov, I. N. and Semin, V. A.(1994). Development and evaluation of new linear equation solvers for phoenics. The PHOENICS J. of Computational Fluid Dynamics and its Applications, 7(1):34-57.

Premoze, S., Tasdizen, T., Bigler, J., Lefohn, A., and Whitaker, R. T.(2003). Particle-based simulation of fluids. In Eurographics 2003, Granada, Spain. European Association for Computer Graphics.

Saad, Y. and Schultz, M.(1986). Gmres: A generalized minimal residual algorithm for solving nonsymmetric linear systems. SIAM Journal on Scientific Computing, 7:856-869.

Shibata, K., Koshizuka, S., and Oka, Y.(2004). Numerical analysis of jet breakup behavior using particle method. Journal of Nuclear Science and Technology, 41(7):715-722.

Sueyoshi, M. and Naito, S.(2002a). Application of mps method to violent free surface problems on marine engineering. Department of Naval and Ocean Engineering, Graduate School of Engineering, Osaka University.

Sueyoshi, M. and Naito, S.(2002b). A numerical study of very large motion of floating body by particle method. In Asia Pacific Maritime Congress, pages 146-150, Kobe, Japan. Asia Pacific Workshop on Marine Hydrodynamics.

Umegaki, K., Takahashi, S., and Miki, K.(1992). Numerical simulation of incompressible viscous flow using particle method. IPSJ SIGNotes Numerical Analysis, 043-003:17.

van der Vorst, H.(1992). Bi-cgstab: A fast and smoothly converging variant of bi-cg for the solution of nonsymmetric linear systems. SIAM Journal on Scientific Computing, 13:631644. 
Voevodin, V.(1983). The problem of non-self-adjoint generalization of the conjugate gradient method is closed. U.S.S.R. Computational Mathematics and Mathematical Physics, 23:143144.

Xie, H., Koshizuka, S., and Oka, Y.(2004). Numerical simulation of liquid drop deposition in annular-mist flow regime of boiling water reactor. Journal of Nuclear Science and Technology, 41(5):569-578. 